\title{
Improved Consistency of Climate Projections over Europe after Accounting for Atmospheric Circulation Variability ${ }^{\circ}$
}

\author{
Claudio SAFFioti, ERICH M. Fischer, AND RETO KNUTTI \\ Institute for Atmospheric and Climate Science, ETH Zürich, Zurich, Switzerland
}

(Manuscript received 27 September 2016, in final form 9 June 2017)

\begin{abstract}
The influence of atmospheric circulation on winter temperature and precipitation trends over Europe in the period 2006-50 is investigated in a 21-member initial condition ensemble from a fully coupled global climate model and in a multimodel framework consisting of 40 different models. Five versions of a dynamical adjustment method based on empirical orthogonal function analysis of sea level pressure are introduced, and their performance in removing the effect of atmospheric circulation on temperature and precipitation is tested. The differences in atmospheric circulation as simulated by different models in their control runs and under the historical and representative concentration pathway 8.5 (RCP8.5) forcing scenarios are investigated. Dynamical adjustment is applied to the multimodel ensemble to demonstrate that a substantial fraction of the uncertainty in projected European temperature and precipitation trends is explained by atmospheric circulation variability. A statistically significant response of sea level pressure to anthropogenic forcing is identified in the multimodel ensemble under the RCP8.5 scenario. This forced response in atmospheric circulation is associated with a dynamical contribution to the long-term multimodel mean temperature and precipitation trends. The results highlight the importance of accounting for the impact of atmospheric circulation variability on trends in regional climate projections.
\end{abstract}

\section{Introduction}

\section{a. Uncertainty in climate change projections}

Uncertainty in climate projections arises from three different sources, namely model uncertainty, the future evolution of emissions of greenhouse gases and aerosols, and internal climate variability (Knutti et al. 2008; Knutti and Sedláček 2012; Hawkins and Sutton 2009, 2011; Murphy et al. 2004). Internal (unforced) variability refers to fluctuations occurring in the absence of any external forcing as a result of the interaction between the various components of the climate system. It represents the dominant source of uncertainty for the first decade in regional climate projections everywhere on the globe, and for several decades ahead in many areas of the planet, both in global and regional simulations

Supplemental information related to this paper is available at the Journals Online website: http://dx.doi.org/10.1175/ JCLI-D-16-0695.s1.

Corresponding author: Claudio Saffioti, claudio.saffioti@env. ethz.ch
(Palmer et al. 2004; Shukla 1998; Deser et al. 2012a). The effect of anthropogenic climate change can be regionally obscured or enhanced by internal variability even on time scales of several decades (Saffioti et al. 2016; Deser et al. 2012b). As a consequence, the identification of the anthropogenic forced response is particularly difficult at small spatial and temporal scales (Deser et al. 2014, 2016; Solomon et al. 2011). The attention of the scientific community to the role of internal variability has therefore been increasing in recent years, also in relation to the concern of making available to policy makers reliable regional climate projections for the upcoming decades (Doblas-Reyes et al. 2013).

\section{b. Internal variability and the forced response in model simulations}

Model simulations can be used to identify the climate impact of external forcing factors such as greenhouse gases, tropospheric aerosols, and ozone-depleting substances. Initial condition ensembles are obtained by running the same climate model multiple times under the same forcing conditions but from different perturbed initial states. On the contrary, multimodel ensembles are obtained by running simulations from 
different models. The identification of the forced signal in such simulations is usually carried out by removing the effect of internal variability through ensemble averaging (Tebaldi and Knutti 2007). If a sufficient number of model simulations are available, each of them characterized by a different realization of internal variability, the ensemble mean is usually taken as an estimate of the forced response. The effect of internal variability in each run of an initial condition ensemble from a single model can be identified as the departure of each simulation from the ensemble mean. However, this procedure is not applicable to a multimodel ensemble, in which differences between simulations are caused not only by internal variability but also by parametric and structural differences among models (Masson and Knutti 2011; Knutti et al. 2010; Collins et al. 2011; Murphy et al. 2004; Stainforth et al. 2005; Pennell and Reichler 2011; Jun et al. 2008). In addition, many models are not fully independent from each other, as they often share similar versions of the same components (Masson and Knutti 2011; Knutti et al. 2013). This common genealogy limits the effective number of degrees of freedom in a multimodel ensemble (Pennell and Reichler 2011). Nonetheless, there is a substantial diversity of model behaviors in representing the forced response, as well as variability from diurnal to decadal and centennial time scales (Randall et al. 2007; Stoner et al. 2009; Lucarini et al. 2007). Similarly, daily to interannual temperature variability in Europe has been shown to differ substantially between simulations (Kjellström et al. 2007; Fischer and Schär 2009; Jacob et al. 2007). Several previous studies highlighted the strong influence of atmospheric circulation on temperature and precipitation changes in model simulations (Deser et al. 2014; Frankcombe et al. 2015) and in observations (Hurrell 1996; Thompson et al. 2009; Smoliak et al. 2015; Cattiaux et al. 2010; Ceppi et al. 2012; Wallace et al. 1995; Vautard and Yiou 2009; Saffioti et al. 2016).

\section{c. Dynamical adjustment methods}

Dynamical adjustment methods identify and remove the contribution of atmospheric circulation from a field of interest, typically temperature or precipitation. A variety of approaches to dynamical adjustment are discussed in the literature. Among others, a constructed analog technique was applied to identify the dynamical contribution to multidecadal surface air temperature trends over North America as simulated by an initial condition ensemble from the Community Earth System Model (Deser et al. 2016). The constructed analog technique relies on a modified version of the constructed circulation analog method (Van den Dool 1994), which identifies and groups together similar circulation patterns (Lorenz 1969). A dynamically adjusted global mean temperature time series was estimated by accounting for the influence of the North Atlantic Oscillation and El Niño-Southern Oscillation (ENSO) (Hurrell 1995). The effect of ENSO on the global temperature record has been estimated using various approaches, including regression models (e.g., Trenberth 2002) and maximum covariance analysis (Yang and Schlesinger 2001). Several methods were applied by Thompson et al. (2009) to remove from the observed global mean temperature record the signature of natural climate variability related to ENSO and to the differential advection of warm and cold air masses over land and ocean. Principal component-based indices of the northern annular mode (NAM) and the Pacific-North American (PNA) pattern were used by Quadrelli and Wallace (2004) to identify their influence on observed temperature trends and variability. Principal component analysis was also applied by Thompson et al. (2000) to estimate the impact of the NAM on multidecadal temperature and precipitation trends in the Northern Hemisphere.

Smoliak et al. (2015) quantified the influence of atmospheric circulation on temperatures in the Northern Hemisphere using a dynamical adjustment approach based on partial least squares regression, a statistical method maximizing the covariance between the predictor and predictand fields (Abdi 2010; Smoliak et al. 2010). This was also adopted to assess the role of atmospheric circulation in the pronounced wintertime warming at high latitudes in the Northern Hemisphere observed in the late twentieth century (Wallace et al. 2012). Frankcombe et al. (2015) applied a scaling method to model simulations to separate the signature of internal variability from the externally forced climate response.

The approach of superposing internal variability upon the forced signal in multimodel projections is simple but relies on the assumption that forced changes in the amplitude and patterns of variability are small compared to its unforced properties, so that variability can be considered approximately additive to the forced response. There are cases, however, in which the assumption of linearity fails to hold (Corti et al. 1999; Palmer 1999; Hsu and Zwiers 2001; Stephenson et al. 2004; Gillett et al. 2005; Gillett and Fyfe 2013).

\section{d. Aims and outline of the study}

Here we describe five versions of an EOF-based dynamical adjustment method and we test their performance in quantifying the fractional uncertainty in trends induced by atmospheric circulation variability. To this end we disentangle the effect of atmospheric circulation 
from the forced response of temperature and precipitation over Europe as simulated by 40 models from phase 5 of the Coupled Model Intercomparison Project (CMIP5) (Taylor et al. 2012) in the period 2006-50. We show that the uncertainty in future projections of temperature and precipitation over Europe can be reduced by accounting for the effect of circulation. In addition, we identify a statistically significant response of atmospheric circulation to anthropogenic forcing in the CMIP5 multimodel ensemble, and we quantify its effect on projected temperature and precipitation trends over Europe. Several previous studies used empirical orthogonal function analysis to quantify the influence of internal variability on climatological fields (e.g., Quadrelli and Wallace 2004; Saffioti et al. 2016; Thompson et al. 2000), but to the best of the authors' knowledge a systematic comparison of the various versions of such an approach has never been published. Most of the previous studies estimating the influence of internal variability on multidecadal trends analyzed this effect on North America (Deser et al. 2012a, 2016) or on a global scale (Deser et al. 2012b; Thompson et al. 2015). This work quantifies the effect of circulation on projected trends over Europe. Results obtained from both an initial condition ensemble and a multimodel ensemble are presented.

This study is structured as follows. The model simulations are described in section 2 . In section 3 we introduce five versions of a dynamical adjustment method based on empirical orthogonal function analysis of sea level pressure (SLP) in the winter season [December-February (DJF)], and we compare their performance in reducing the uncertainty on future winter temperature and precipitation trends over Europe. In section 4 we investigate the differences in winter atmospheric circulation as simulated by 40 CMIP5 models in their control integrations and under historical and representative concentration pathway 8.5 (RCP8.5) forcing scenarios. Dynamical adjustment is then applied to the multimodel ensemble in order to identify the impact of atmospheric variability on winter temperature and precipitation trends over Europe in the period 2006-50. In section 5 we identify a statistically significant response of circulation to anthropogenic forcing as sampled from winter SLP data over the EuroAtlantic sector. The implications of such a response for the application of dynamical adjustment are discussed. In section 6 conclusions are drawn.

\section{Model simulations}

We analyze a 21-member initial condition ensemble from the Community Earth System Model (CESM), version 1.0.4, using the Community Atmosphere Model, version 4
(CAM4), and fully coupled ocean, sea ice, and land components (Hurrell et al. 2013). Simulations are initialized on 1 January 1950 with slightly different atmospheric initial conditions and run through year 2100 under historical (1950-2005) and RCP8.5 (2006-2100) forcing. Details on the 21-member initial condition ensemble (hereafter named CESM-IC) are presented in Fischer et al. (2013).

Simulations from 40 models of CMIP5 are also analyzed (Taylor et al. 2012). These are initialized on 1 January 1850 and adopt historical forcing through year 2005 and the RCP8.5 scenario afterward. Table A1 in the appendix lists the 40 CMIP5 models included in this study. Only the first simulation (r1i1p1) from each of them is analyzed, and years prior to 1960 are excluded for consistency with CESM-IC.

We make use of the last 100 years of the preindustrial control simulations of all the models mentioned so far, together with their integrations for the years 1960-2099. To allow for a direct comparison, all simulations in the CMIP5 ensemble are interpolated to the latitudelongitude grid used in CESM-IC with a resolution of $1.9^{\circ} \times 2.5^{\circ}$.

\section{Five versions of dynamical adjustment and their performance}

Figure 1 shows the 2006-50 winter (DJF) temperature trends over Europe as simulated by the two runs from the 21-member CESM-IC, differing only in their atmospheric initial conditions, with the highest (ens02-im128; Fig. 1a) and lowest (ens01-im128; Fig. 1d) area-average trends over the region $33^{\circ}-75^{\circ} \mathrm{N}, 10^{\circ} \mathrm{W}-40^{\circ} \mathrm{E}$, along with the multimember ensemble average (Fig. 1g). Contour lines indicate the corresponding sea level pressure trends in the domain $25^{\circ}-85^{\circ} \mathrm{N}, 40^{\circ} \mathrm{W}-70^{\circ} \mathrm{E}$. The run with the strongest warming is characterized by an amplified European average trend of $0.44^{\circ} \mathrm{C}$ decade ${ }^{-1}$, almost twice as large as the ensemble average trend $\left(0.26^{\circ} \mathrm{C}\right.$ decade $\left.^{-1}\right)$, while the run with the weakest warming has an area-average trend of $0.05^{\circ} \mathrm{C}$ decade $^{-1}$, with cooling over Scandinavia and central Europe.

Analogous results for precipitation are shown in Figs. 2a,d,g, reporting the results from the two simulations with the highest (ens04-im64) and the lowest (ens17-im64) area-average trends in precipitation. The influence of natural variability produces positive or negative area-average precipitation trends over Europe in the period 2006-50. The run with the strongest increase in precipitation $\left(1.7 \%\right.$ decade $^{-1}$; Fig. $\left.2 \mathrm{a}\right)$ shows pronounced wettening over southern Europe. This is in contrast with the simulated ensemble average, characterized by drying over the Mediterranean region and wettening at higher latitudes resulting in a near-zero 
(a)

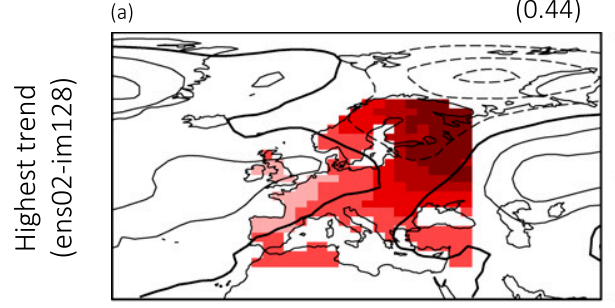

(b)

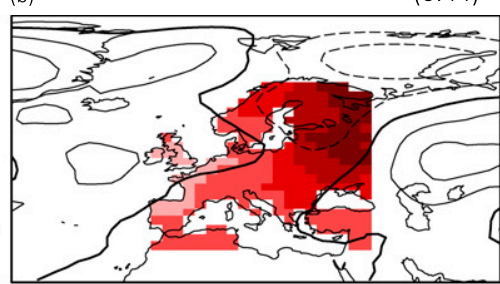

(c)

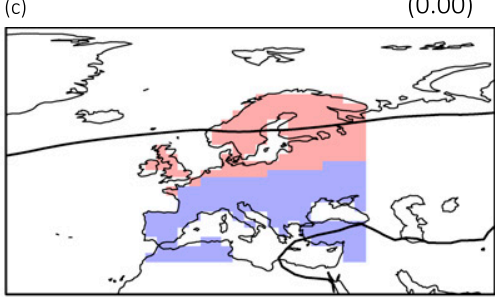

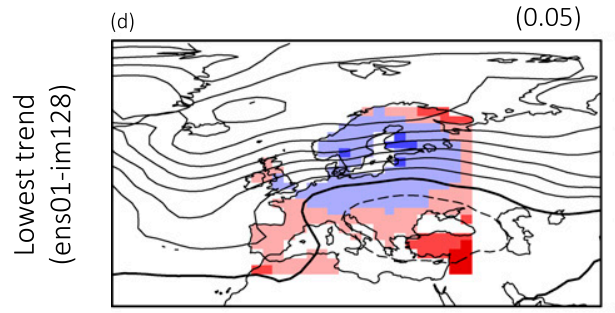

(e)

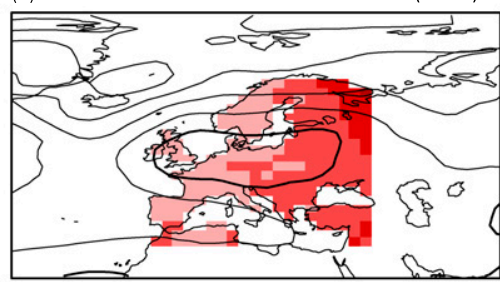

(0.24)

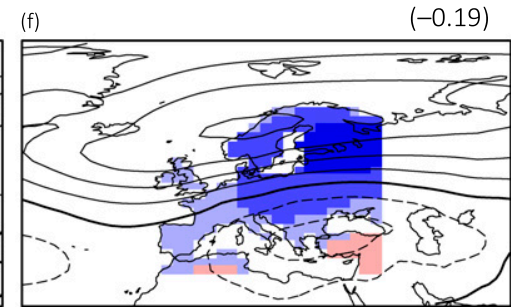

(g)

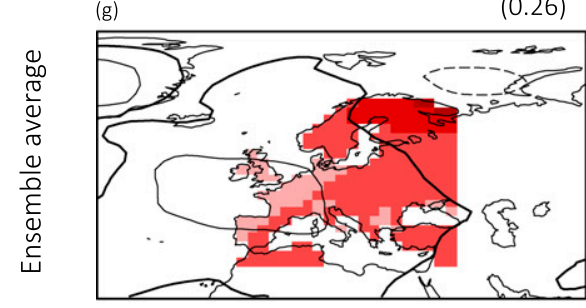

(h)

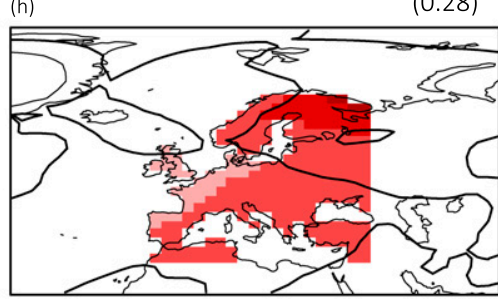

(i)

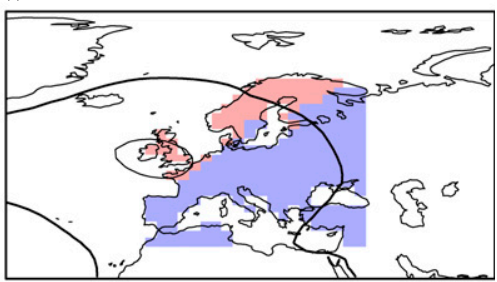

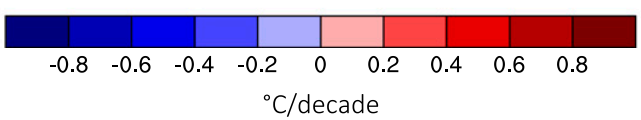

Contours: $0.2 \mathrm{hPa} /$ decade

FIG. 1. Temperature trends $\left({ }^{\circ} \mathrm{C}\right.$ decade $\left.^{-1}\right)$ in the period $2006-50$ computed from (left) the original CESM-IC runs, (center) after applying dynamical adjustment, and (right) their differences resulting from the dynamical contribution of the first four modes of atmospheric circulation. Results are shown for the model simulations with the (a)-(c) highest and (d)-(f) lowest weighted area-average trends over the domain and for (g)-(i) the ensemble average. Numbers in parentheses at the top right of each panel indicate the weighted area average of temperature trends. Contour lines indicate sea level pressure trends from the original data at (left), after applying dynamical adjustment at (center), and their differences resulting from the dynamical contribution of the first four modes of circulation at (right). The contour interval is $0.2 \mathrm{hPa}$ decade ${ }^{-1}$. Solid and dashed lines indicate positive and negative values, respectively. Thick lines indicate zero trends.

area-average trend (Fig. $2 \mathrm{~g}$ ). The trends in the run with the most pronounced drying $\left(-2.0 \%\right.$ decade $^{-1}$; Fig. $\left.2 \mathrm{~d}\right)$ have a pattern similar to the ensemble average but are characterized by an enhanced drying over the Mediterranean region. The diversity of the trends simulated by CESM-IC is purely a consequence of internal variability and can largely be removed by dynamical adjustment as shown below.

\section{a. Five versions of dynamical adjustment}

We compare the efficiency of five versions of dynamical adjustment that share the same underlying method. In all of these versions the main modes of atmospheric circulation are identified by performing an empirical orthogonal function (EOF) analysis of simulated SLP data. The principal component time series of each EOF is then linearly regressed upon temperature and precipitation data at every model grid point, thus estimating the mean effect of each mode of SLP variability on the two fields. The time-varying contribution of each EOF on temperature and precipitation is computed by multiplying its regression maps by the corresponding principal component. This contribution is then removed from the original fields, obtaining a 

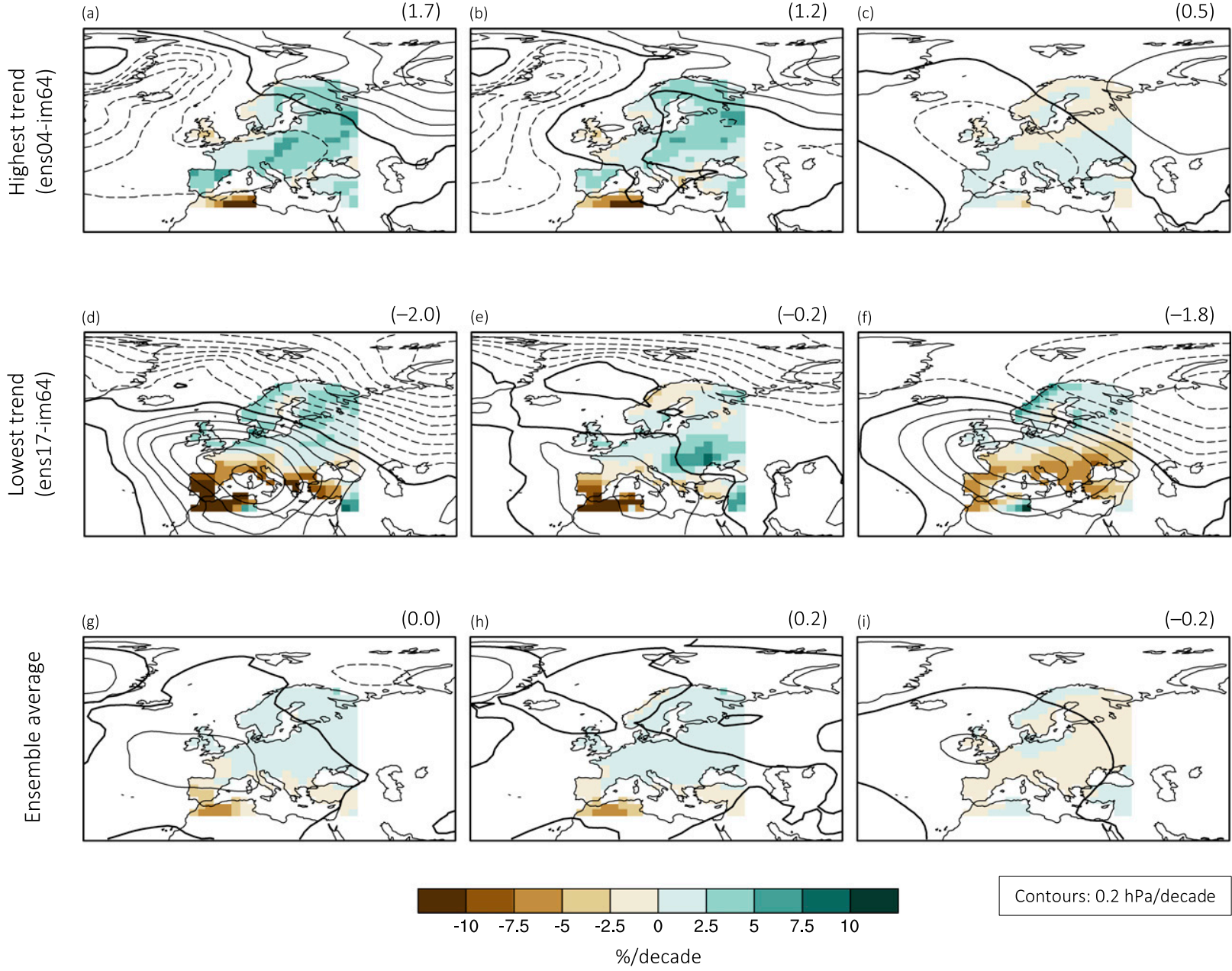

Contours: $0.2 \mathrm{hPa} /$ decade

FIG. 2. As in Fig. 1, but showing results for precipitation trends $\left(\%\right.$ decade $\left.^{-1}\right)$ computed from the model simulations. Numbers in parentheses at the top right of each panel indicate the weighted area average of precipitation trends $\left(\% \mathrm{decade}^{-1}\right)$.

new set of dynamically adjusted data. Note that analogous EOF-based approaches previously appeared in literature under the name of principal component regression (PCR), as described among others by Casty et al. (2005).

The five versions of dynamical adjustment are EOFs and regression maps computed from control data (CTL), from historical data $(\mathrm{H})$, from historical and RCP8.5 data (HR), from detrended historical and RCP8.5 data (DET), and from trends from historical and RCP8.5 data (TRE). These five versions are applied to CESM-IC to test their efficiency in reducing the spread of winter (DJF) temperature and precipitation trends in the $45-y r$ period $2006-50$ simulated by the initial condition ensemble. CESM-IC is composed of simulations affected by independent realizations of internal variability whose characteristics are common to all runs. This makes it the ideal framework for comparing the performance of the five versions of dynamical adjustment. The modes of winter circulation are identified by performing an empirical orthogonal function analysis on DJF monthly mean sea level pressure data over the region $25^{\circ}-85^{\circ} \mathrm{N}, 40^{\circ} \mathrm{W}-70^{\circ} \mathrm{E}$, encompassing Europe and the eastern sector of the North Atlantic Ocean. To weight variance by area, prior to performing the EOF analysis SLP data are multiplied by the square root of the cosine of latitude. Anomalies of winter SLP and temperature in the CESM control integration are computed as the differences from the corresponding monthly averages over the last 100 years of the simulation. Winter precipitation anomalies in the control are computed as percent change relative to monthly mean values in the last 100 years of the integration. In an analogous way, 
monthly sea level pressure, temperature, and precipitation anomalies in years 1960-2100 are estimated from each run separately with respect to the average values computed in the baseline period 1960-2004. The details of each version of dynamical adjustment are described below.

1) For CTL, atmospheric circulation variability is sampled from the last 100 years of the control integration by performing an EOF analysis on DJF monthly SLP anomalies. The effect of each EOF is estimated by linearly regressing monthly temperature and precipitation anomalies from the last 100 years of the control integration on the corresponding principal component time series. A new set of principal components is computed for each run by projecting the DJF monthly SLP anomalies in the period 2006-50 on the EOFs computed from the control. These new principal components are also referred to as "pseudo-principal components." The temperature and precipitation anomaly fields related to each mode of circulation are estimated by multiplying its pseudo-principal component by the regression maps from the control, and these timevarying contributions are subtracted from the original data. The adjusted winter temperature and precipitation trends in years 2006-50 are finally computed for each run. CTL is introduced with the aim of sampling unforced atmospheric circulation variability, thus excluding the influence of anthropogenic forcing or other effects (e.g., radiative imbalances caused by volcanic eruptions).

2) For $H$, as in the CTL version, but EOFs and regression maps are estimated from DJF monthly data in the period $1960-2005$. $\mathrm{H}$ is introduced to study the performance of dynamical adjustment when this is applied to historical data (e.g., from model simulations, reanalysis, or observational datasets).

3) For HR, as in the CTL version, but EOFs and regression maps are estimated from DJF monthly data in the period 1960-2050. HR is introduced to test how the performance of dynamical adjustment changes if data from the adjustment period are included when sampling circulation and its effect on temperature and precipitation.

4) For DET, as in the H version, but linear detrending is applied to monthly DJF sea level pressure, temperature, and precipitation anomalies in the period 19602050. EOFs and regression maps are thus computed from data in the period 1960-2005, and principal components are defined in the period 1960-2050. DET is introduced in the attempt to remove the forced response from sea level pressure, temperature, and precipitation data before identifying the modes of circulation and their effect on the variables of interest. Note that the effect of natural variability on trends can be prominent, depending on the length of the period, the variable, and the region in study.

5) For TRE, in contrast to the monthly time series used in the other versions, trend patterns from an ensemble of simulations are used as a basis for the calculation of EOFs. Winter SLP, temperature, and precipitation trend patterns are computed from each of the 21 simulations in the two 45 -yr periods 1960 2004 and 2006-50, thus obtaining a set of 42 trend fields for each variable. The adjusted 2006-50 trend from each CESM run is estimated after performing an EOF analysis on the 41 winter mean SLP trend patterns simulated by the 21 runs in the two periods, excluding the 2006-50 trend from the simulation to adjust. Principal components are computed by projecting the SLP trends on each EOF and are regressed on the 1960-2004 and 2006-50 winter mean temperature and precipitation trends simulated by the 21 runs at each grid point, again excluding the 2006-50 trends from the simulation to adjust. The contribution of atmospheric circulation is then removed from the 2006-50 winter temperature and precipitation trends. To avoid overfitting, the information from the trends to adjust is excluded for the dataset used for calibrating dynamical adjustment. The inclusion of trends in the period 19602004 is meant to increase the degrees of freedom of the dataset from which EOFs are computed. Note that the long-term response to anthropogenic forcing might cause a limited degree of correlation between trends in the two periods 1960-2004 and 2006-50 in each run. However, the diversity of trends simulated by CESM-IC in the period 200650 (Figs. 1a,d,g and 2a,d,g) suggests that internal variability dominates over the effect of anthropogenic forcing. Because of the chaotic nature of atmospheric circulation variability, the trends in the two periods can thus be considered largely uncorrelated. TRE is introduced to estimate how longterm changes in SLP affect long-term changes in temperature and precipitation, without accounting for monthly winter variability.

Note that when removing the contribution of circulation from temperature and precipitation data we do not account for the effect related to the lack of orthogonality of the pseudo-principal-component time series. This is not to be considered an issue, as the pseudo-principal 
components are very weakly correlated in both the CESM-IC and the CMIP5 ensembles.

The study of these five versions of dynamical adjustment is motivated by the fact that 1) variability might change over time, 2) forced trends might project onto preexisting patterns of variability, and 3 ) the patterns in decadal variability (as estimated from trends by TRE) might differ from those at interannual time scales (as estimated by CTL, H, HR, and DET). All members of the CESM-IC ensemble are based on the same model and forcing, and they only differ in their realizations of internal variability. This ensemble thus represents an ideal framework for testing the five versions of dynamical adjustment.

\section{b. The contribution of atmospheric circulation to CESM-IC temperature and precipitation trends}

The CESM-IC ensemble averages of the 2006-50 winter temperature and precipitation trends (Figs. 3a and $4 \mathrm{a}$ ) represent the best estimates of the forced response simulated by the model, and a measure of the effect that internal variability has on trends is given by their standard deviation (Figs. 3b and 4b). The ensemble averages and standard deviations of the dynamically adjusted trends are computed after removing the effect of the first four EOFs using the five versions. Results are affected by the number of EOFs included in the analysis. The leading mode of variability has the biggest effect, while the contributions from subsequent EOFs tend to get progressively smaller (see discussion below). By comparing the ensemble averages of the adjusted and of the original trends it is possible to identify regions where dynamical adjustment introduces an offset in the forced response. The offsets introduced by the five versions are compared for temperature and precipitation data in Figs. 3c,e,g,i,k and $4 \mathrm{c}, \mathrm{e}, \mathrm{g}, \mathrm{i}, \mathrm{k}$, respectively, where they are shown as differences between the dynamically adjusted and the original ensemble average trends. The offsets introduced by CTL, H, and HR are of similar magnitude (Figs. 3c,e,g and 4c,e,g). The low values in Figs. $3 i$ and $4 i$ are explained by the fact that in DET the forced response of sea level pressure, temperature, and precipitation is largely removed through detrending. The offsets in Figs. $3 \mathrm{k}$ and $4 \mathrm{k}$ are small because TRE is less efficient than CTL, H, and HR in removing the forced response of sea level pressure.

Figures $3 \mathrm{~d}, \mathrm{f}, \mathrm{h}, \mathrm{j}, 1$ and $4 \mathrm{~d}, \mathrm{f}, \mathrm{h}, \mathrm{j}, 1$ show the percentage differences between the ensemble standard deviations of the adjusted and the original trends. All the five versions reduce the spread in temperature and precipitation trends over most of the region, and they have similar performances in removing the contribution of atmospheric circulation to temperature and precipitation
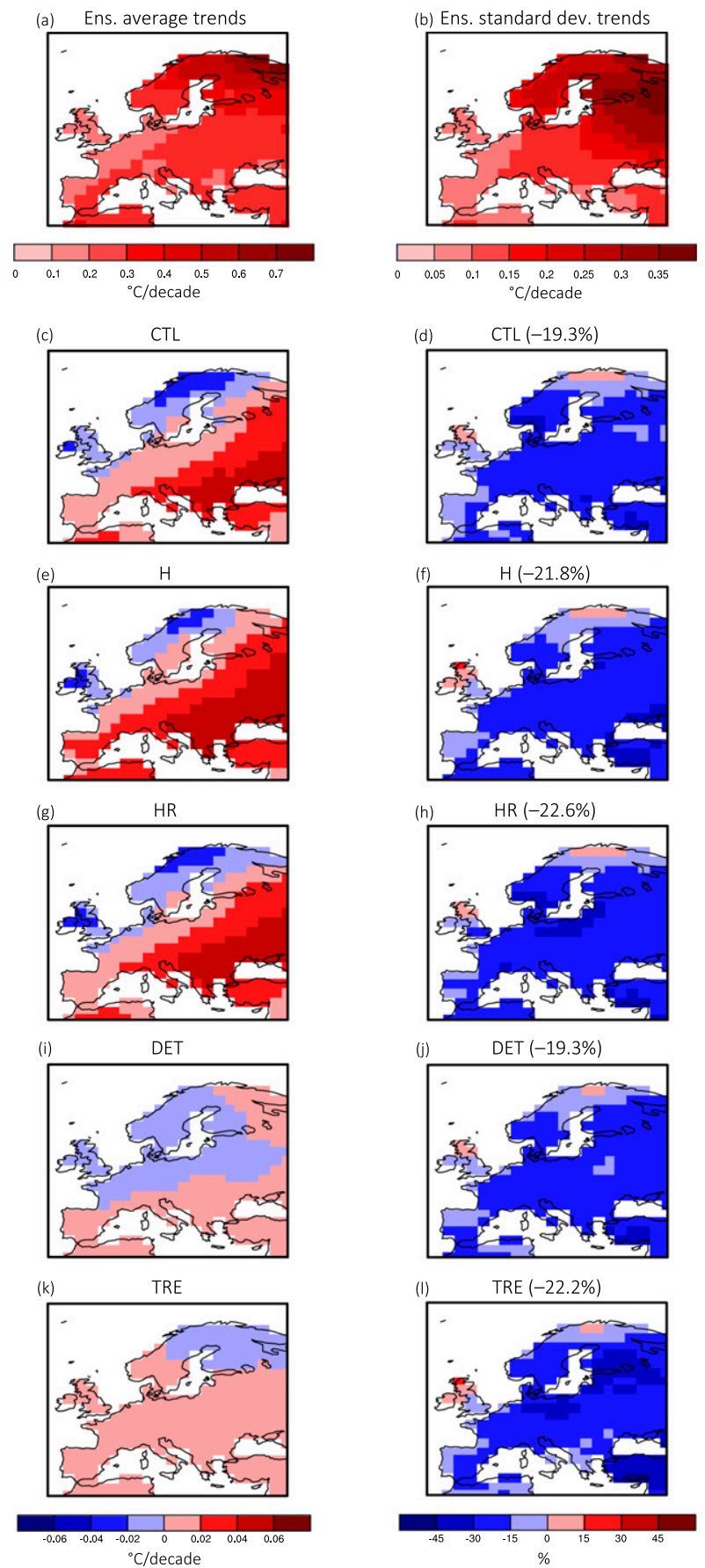

FIG. 3. (a) Ensemble average and (b) standard deviation of winter temperature trends simulated by CESM-IC in the period 2006-50. Offsets in the ensemble average trends introduced by dynamical adjustment are shown as differences between the adjusted and the original ensemble average trends after removing the effect of circulation (four EOFs) with the (c) CTL, (e) H, (g) HR, (i) DET, and (k) TRE versions of dynamical adjustment. (d),(f),(h),(j),(l) Percent change in the standard deviations of trends after removing the effect of circulation. Numbers in parentheses indicate area-average values. 

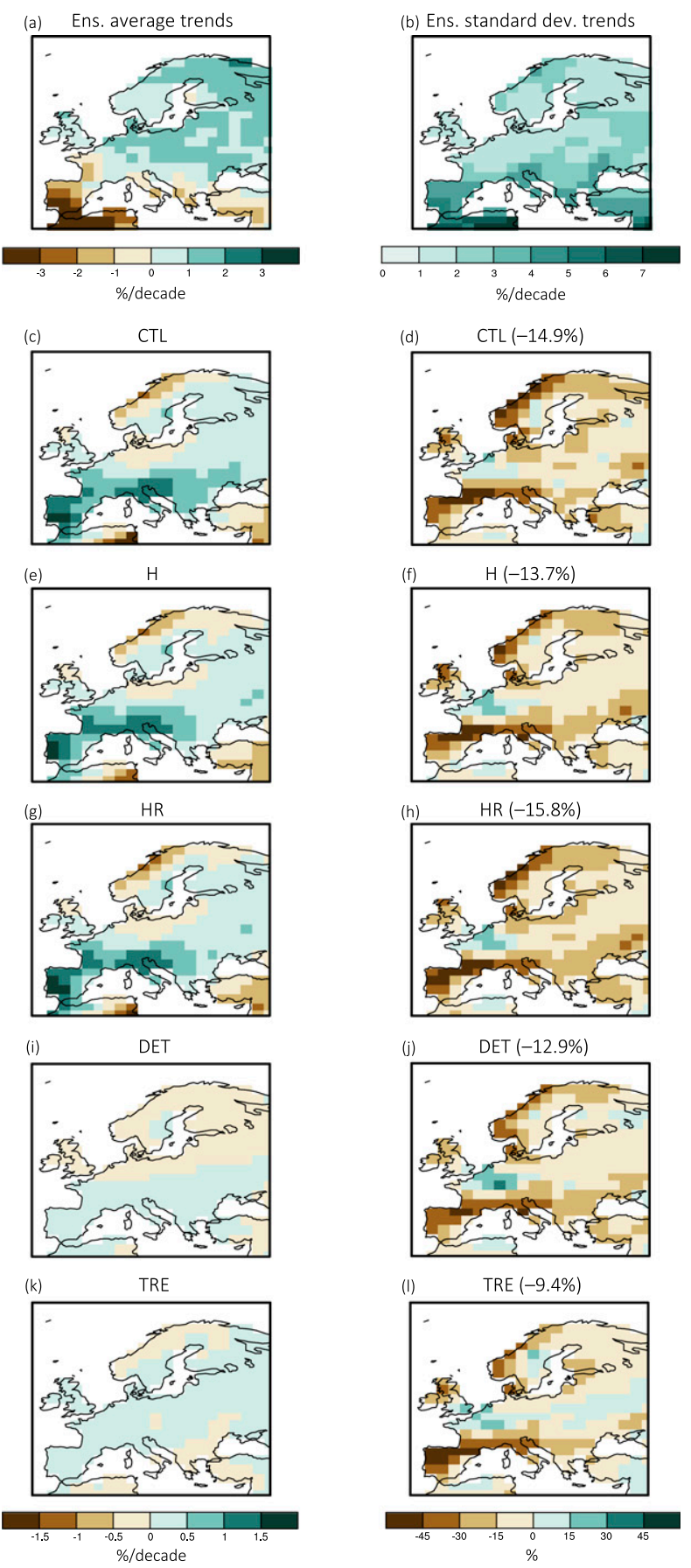

FIG. 4. As in Fig. 3, but showing results for precipitation.

trends. Figure 5 shows the area averages of the standard deviations of the original and adjusted winter temperature and precipitation trends after removing an increasing number of EOFs. The most pronounced reduction in the spread of trends is related to first EOF (EOF1). The standard deviation of the adjusted trends computed with CTL, H, DET, and TRE are characterized by a minimum

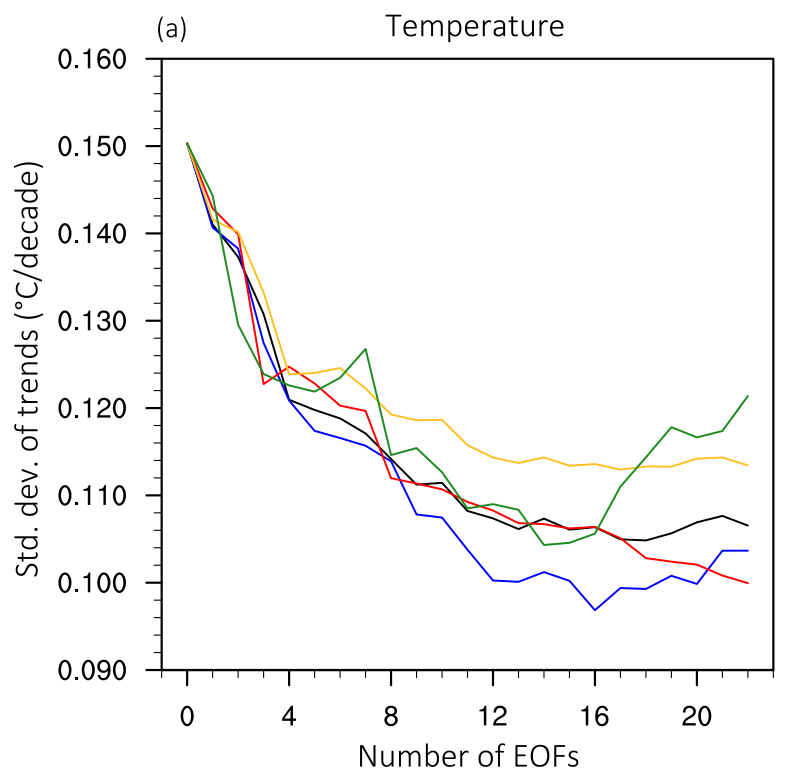

(b)

Precipitation

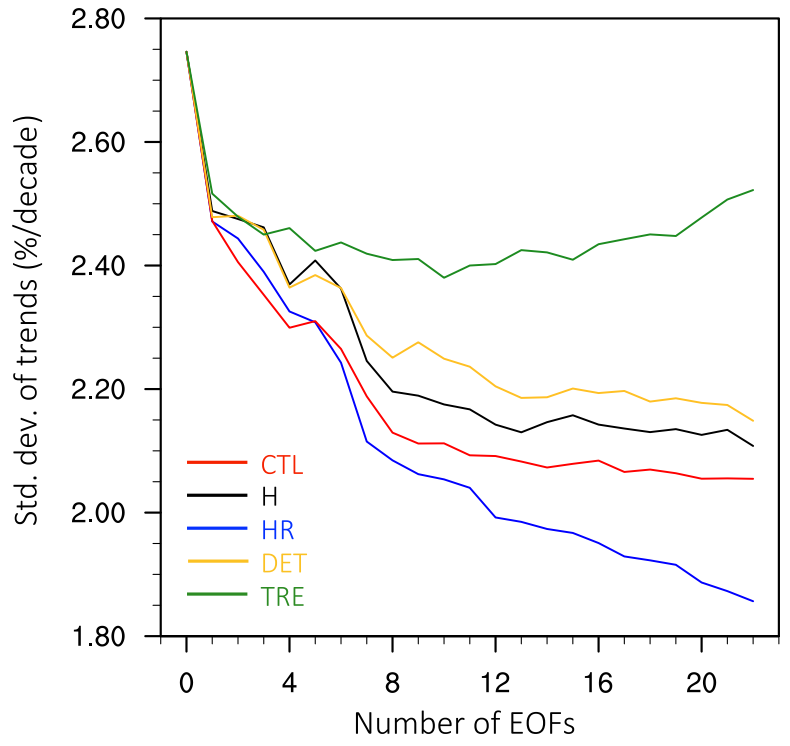

FIG. 5. Performance of the five versions of dynamical adjustment when applied to CESM-IC. Weighted area averages of the ensemble standard deviations of the original and adjusted winter (a) temperature and (b) precipitation trends in the period 2006-50 as a function of the number of EOFs removed. Shown are CTL (red), H (black), HR (blue), DET (yellow), and TRE (green).

and increase again when further EOFs are included in the adjustment. This is evident for TRE, while the minimum for the other three versions is reached at a higher number of EOFs (not shown). On the contrary, the standard deviations of the adjusted trends computed with HR continue to slowly decrease owing to overfitting. However, the performance of $\mathrm{H}$ and $\mathrm{HR}$ are comparable if only a 
small number of EOFs are included in the analysis, suggesting that overfitting in HR is not a major issue. A disadvantage of TRE compared to the other methods is that it requires an ensemble of simulations, while the others can be applied to individual model runs and (with the only exception of CTL) to observations.

In the five versions of dynamical adjustment the EOFs and their regression maps for temperature and precipitation are characterized by similar structures (Fig. S1 in the supplemental material). Analogous results are found for the subsequent modes of variability and regression maps (not shown). Here EOFs are taken as dimensionless, while principal components retain the physical unit of the field (hPa). When computing the effect of each EOF on temperature and precipitation data by linear regression we obtain regression maps whose units are degrees Celsius per hectopascal and percent per hectopascal, respectively. Note that regression maps shown in the supplemental material are computed after dividing the principal components by their standard deviations. Regression maps thus show the effect of each mode of circulation when its principal component has a value equal to its standard deviation.

The CTL method is applied to CESM-IC temperature and precipitation data. The choice of the number of EOFs to include in the analysis is to a large extent arbitrary (Hannachi et al. 2007; North et al. 1982). To define a consistent criterion, we account for the effect of the first EOFs cumulatively explaining at least $80 \%$ of the variability of sea level pressure in the last 100 winters of the preindustrial control simulation. This removes the effect of the first four modes of variability, cumulatively explaining about $81.4 \%$ of the overall SLP variance. The top panels in Fig. S2 of the supplemental material show the EOFs obtained for CESM-IC. Figures $1 b, e, h$ and $2 b$, e,h show the dynamically adjusted winter temperature and precipitation trends over Europe in the period 200650 by the two CESM-IC runs with the highest and lowest area-average trends over the region, along with the ensemble average trends. Contour lines indicate the corresponding sea level pressure trends, which are greatly reduced by the adjustment. The dynamical contributions to the trends in temperature and precipitation are reported in Figs. 1c,f,i and 2c,f,i together with the corresponding SLP trends. These components are additive, so that the original trends are given by the sum of the dynamically adjusted trends and the corresponding dynamical contributions. Sea level pressure variability can either produce warming or cooling in individual simulations. Trends in the run with the weakest warming are primarily caused by SLP variability. In contrast, the positive temperature trends in the warmest run are mainly driven by thermodynamic processes, with the estimated effect of atmospheric circulation variability being positive but close to zero. This is related to the small SLP trends in the period. The ensemble average dynamical contribution to temperature trends (Fig. 1i) is small compared to the effect of circulation in individual runs. Analogous results are found for precipitation, with the run with the lowest area-average trend being strongly influenced by circulation (Fig. 2f) and the ensemble average dynamical contribution (Fig. 2i) being small compared to the effect of SLP variability in individual simulations. Dynamical adjustment reduces the spread of trends simulated by the ensemble. The percent change in the standard deviations of trends in sea level pressure after removing the effect of the first four EOFs with the CTL version is shown in Fig. S3 of the supplemental material. Analogous results for temperature and precipitation are reported in Figs. 3d and 4d. The spread of the adjusted temperature and precipitation trends is not very sensitive to the number of EOFs included in the adjustment (Fig. S4 in the supplemental material).

Dynamical adjustment is also applied on a hemispheric scale. This is done by sampling sea level pressure variability in the domain $15^{\circ}-90^{\circ} \mathrm{N}$ for all longitudes and removing the effect of circulation from temperature and precipitation in the Northern Hemisphere extratropics $\left(30^{\circ}-90^{\circ} \mathrm{N}\right.$ and all longitudes). The percent change in the standard deviations of trends in sea level pressure, temperature, and precipitation after removing the effect of the first four EOFs are shown in Fig. S5 of the supplemental material. Sampling atmospheric circulation on a hemispheric scale allows for a reduction of the spread of SLP, temperature, and precipitation trends. Note that these results are not directly comparable to those in Figs. 3d and S3, as the same number of EOFs are removed from two domains with different geographical extensions.

The residual difference between the dynamically adjusted trends can be largely attributed to variability not sampled by the EOF analysis of sea level pressure and thermodynamic processes such as those related to varying sea ice and snow cover affecting the surface energy budget (Deser et al. 2016).

\section{Atmospheric circulation and its impact on temperature and precipitation trends in a multimodel ensemble}

\section{a. Differences in atmospheric circulation across CMIP5 models}

Differences between trends simulated by an initial condition ensemble from a single model can be uniquely attributed to internal variability. On the contrary, the 
spread of trends in a multimodel ensemble not only is related to different realizations of internal variability but also is a consequence of structural and parametric differences among models, which cause different responses to the same external forcing. Different models also have different representations of atmospheric variability as described by the main modes of circulation and their percentage contribution to the overall variance of sea level pressure. To highlight these differences, an empirical orthogonal function analysis is performed on monthly winter (DJF) SLP anomalies in the last 100 years of the control simulations of each of the 40 CMIP5 models included in the study. Additionally, the main modes of circulation are identified in the dataset obtained by merging the last 100 years from all the control runs. Values higher than 0.90 are found for the weighted pattern correlation (corr) between the multimodel EOF1 and EOF1 from each model, with the only exception of MIROC-ESM (corr $=0.81$ ) and CSIRO Mk3.6.0 (corr $=0.88$ ). These very high values suggest that the multimodel EOF1 is representative of the average circulation patterns across the ensemble and it is not strongly affected by circulation differences between models. Figure 6 shows the leading EOF over the EuroAtlantic region in the CMIP5 multimodel case (top) and in each of the 40 models (remaining panels). In all cases the leading mode of circulation resembles the North Atlantic Oscillation (Hurrell 1995), although the position, the intensity, and the extension of its two pressure centers vary substantially across models. The percentage of the overall variance of SLP over the region accounted for by the first mode depends on the model, ranging from $30.0 \%$ (MIROC5) to $46.1 \%$ (NorESM1-M). In all cases, the leading EOFs in Fig. 6 result to be nondegenerate when applying North's rule of thumb (North et al. 1982). They can thus be considered a robust estimate of the main mode of variability, not affected by large sampling fluctuations. Figures S6 and S7 in the supplemental material show the corresponding regression maps for temperature and precipitation computed by merging the last 100 years of the preindustrial control simulations of all CMIP5 models (top panels) and the first regression map from each (remaining panels). In all cases a positive phase of the leading mode of circulation is associated with warming over most of the region and cooling over the southern part of the domain, although the intensity and the geographical features of this effect vary across models (Fig. S6). Analogous results are found for the first regression maps of precipitation, with a common pattern (positive and negative precipitation anomalies over the northern and southern part of the domain) whose details vary across the CMIP5 ensemble (Fig. S7). Differences in the structure of the leading EOF strongly affect its impact on temperature and precipitation, especially over regions where the regression maps change sign (i.e., over the Mediterranean area for temperature and over central Europe for precipitation). Analogous results are found for the subsequent modes of variability and their regression maps (not shown).

\section{b. The effect of atmospheric circulation on CMIP5 temperature and precipitation trends}

In a multimodel experiment like CMIP5 an important question is what fraction of the spread in the projected trends is due to internal variability and what fraction is due to model differences. We apply the CTL method to adjust temperature and precipitation trends in the period 2006-50 as simulated by the 40 CMIP5 models. CTL is chosen as it permits estimating the EOFs and the regression maps without including the influence of anthropogenic forcing. Atmospheric circulation and its regression maps are thus sampled from each control run separately and the first six EOFs are included in the adjustment, explaining at least $80 \%$ of sea level pressure variability in all control simulations. Note that by sampling atmospheric circulation from the control integration and adjusting trends computed from the RCP8.5 scenario we avoid the problem of dealing with discontinuities in the historical radiative forcing produced by volcanic eruptions, causing abrupt changes in the concentration of stratospheric aerosols (Robock 2000).

Figures $7 \mathrm{a}, \mathrm{d}, \mathrm{g}$ show the temperature trends simulated by the models showing the strongest (ACCESS1.0) and weakest (MPI-ESM-MR) warming in the ensemble, along with the multimodel average (as in Fig. 1 but for a multimodel rather than an initial condition ensemble). The dynamically adjusted trends (Figs. $7 \mathrm{~b}, \mathrm{e}, \mathrm{h}$ ) and the dynamical contributions (Figs. 7c,f,i) are also shown and the corresponding SLP trends are reported in contours. Analogous results for precipitation are shown in Fig. 8, with CanESM2 and FIO-ESM being the models respectively simulating the most pronounced positive and negative trends in precipitation. Figure 9 shows the percent change in the standard deviations of trends across all CMIP5 models after applying dynamical adjustment (six EOFs). Removing the effect of circulation allows an area-average reduction of the spread of trends over Europe of about $11 \%$ for temperature and $18 \%$ for precipitation. These performances can be compared to those obtained over the same domain when adjusting the CESM-IC ensemble (Figs. 3d, 4d, and S3).

The relative contribution of atmospheric circulation to the spread of temperature trends is more pronounced in CESM-IC than in the multimodel ensemble. The spread across CESM-IC trends only relates to internal 


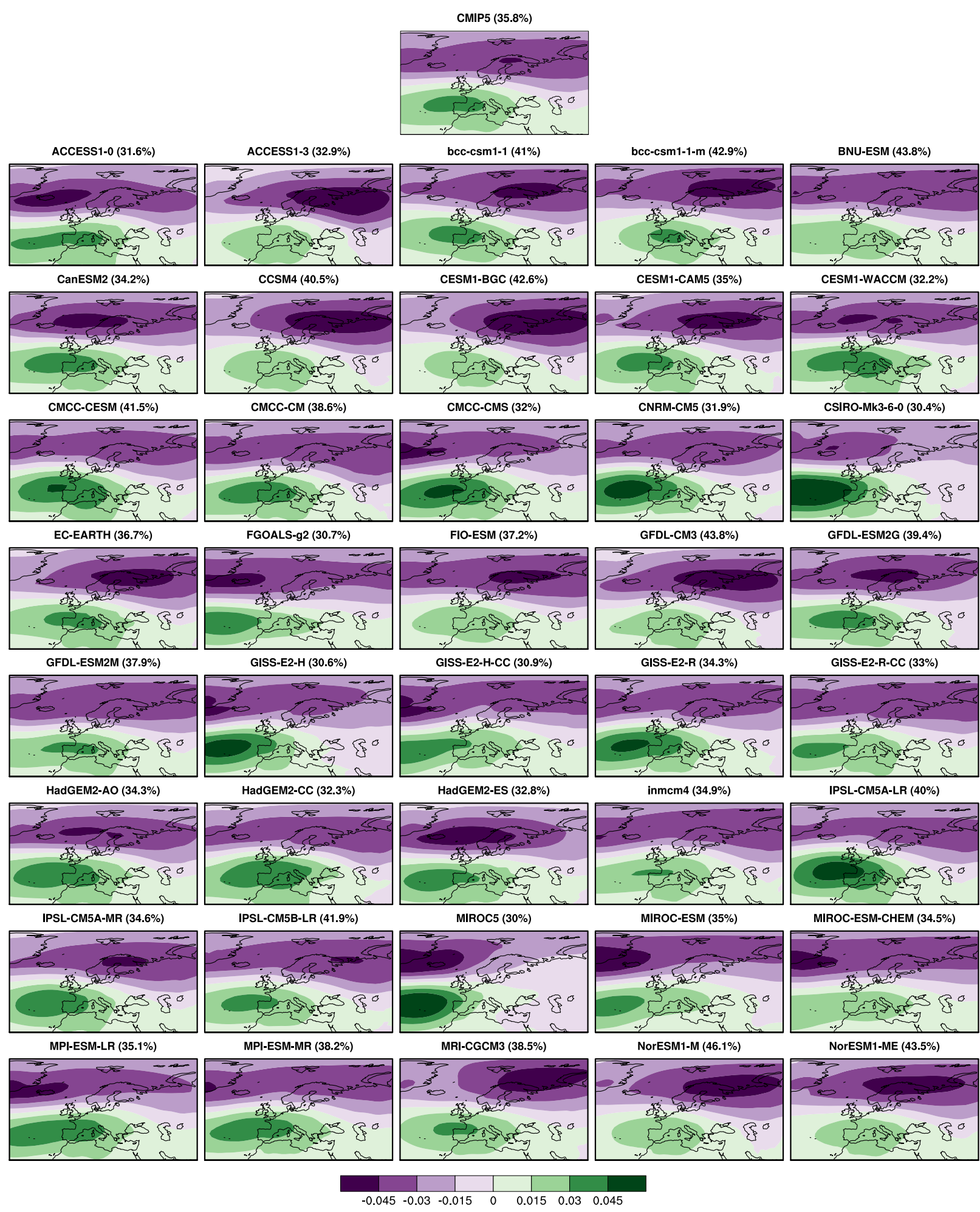

FIG. 6. The first EOF of monthly winter sea level pressure (dimensionless) computed (top) by merging the last 100 years of the preindustrial control simulations of all CMIP5 models and from the last 100 years of the control simulation of each model in the remaining panels. The percentage of the overall variance of sea level pressure explained by each EOF is indicated in parentheses. 
(a)

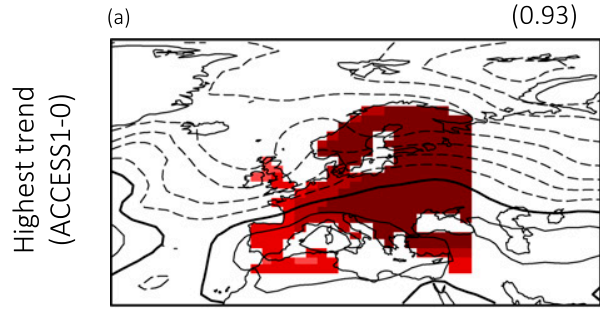

(b)

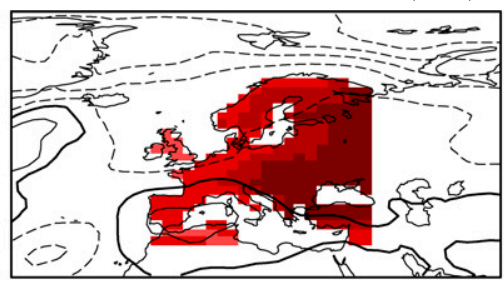

(c)

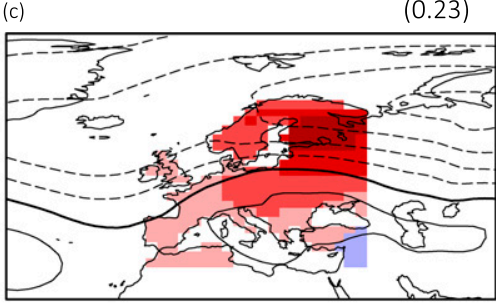

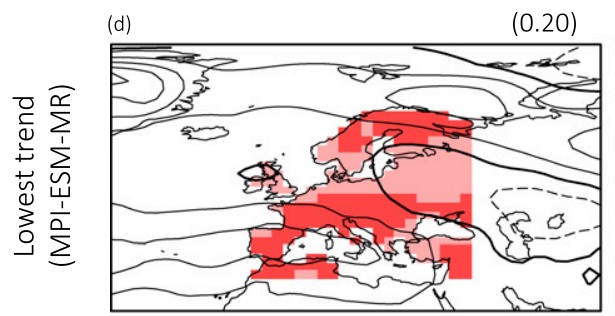

(e)

(0.23)

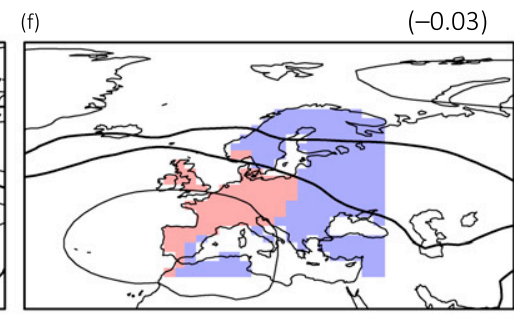

(g)

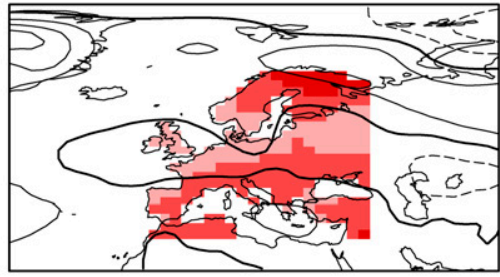

(0.47)

(h)

(0.44)
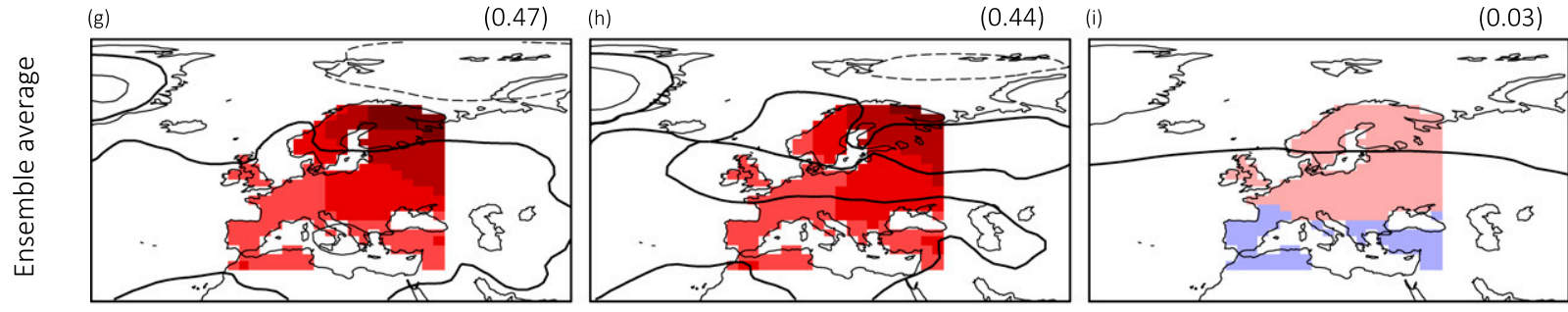

0.03)

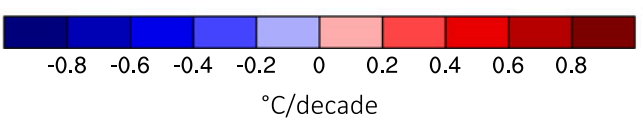

Contours: $0.2 \mathrm{hPa} /$ decade

FIG. 7. Temperature trends $\left({ }^{\circ} \mathrm{C}\right.$ decade $\left.{ }^{-1}\right)$ in the period $2006-50$ computed from (left) the original CMIP5, (center) after applying the CTL version to dynamical adjustment, and (right) their differences resulting from the dynamical contribution of the first six modes of atmospheric circulation. Results are shown for the model simulations with the (a)-(c) highest and (d)-(f) lowest weighted area-average trends over the domain and for (g)-(i) the ensemble average. Numbers in parentheses at the top right of each panel indicate the weighted area-average of temperature trends. Contour lines indicate sea level pressure trends from the original data at (left), after applying dynamical adjustment at (center), and their differences resulting from the dynamical contribution of the first six modes of circulation at (right). The contour interval is $0.2 \mathrm{hPa}$ decade $^{-1}$. Solid and dashed lines indicate positive and negative values, respectively. Thick lines indicate zero trends.

variability, whereas the spread across trends in CMIP5 models also arises from parametric and structural differences leading to different forced warming rates. On the contrary, the reduction in the spread of trends simulated by CESM-IC and CMIP5 is similar for sea level pressure and precipitation data. This suggests that the effect of model differences on trend spread is more pronounced for temperature than for SLP and precipitation. The reduction in the spread of trends depends on the region. This is consistent with previous studies discussing the impact of internal variability on projections over different areas of the globe (Hawkins and
Sutton 2009,2011). A stronger reduction in the spread of trends is generally found for precipitation than temperature, as for the former the effect of natural variability is larger compared to the forced signal. Dynamically adjusted trends are closer to the multimodel average forced response, but in contrast to CESM-IC the spread reduction in the adjusted CMIP5 trends is not only caused by the removal of SLP variability. As the EOFs and the regression maps are sampled from each control run separately, the effect of different modes of atmospheric circulation as simulated by each of the CMIP5 models is removed from data. 

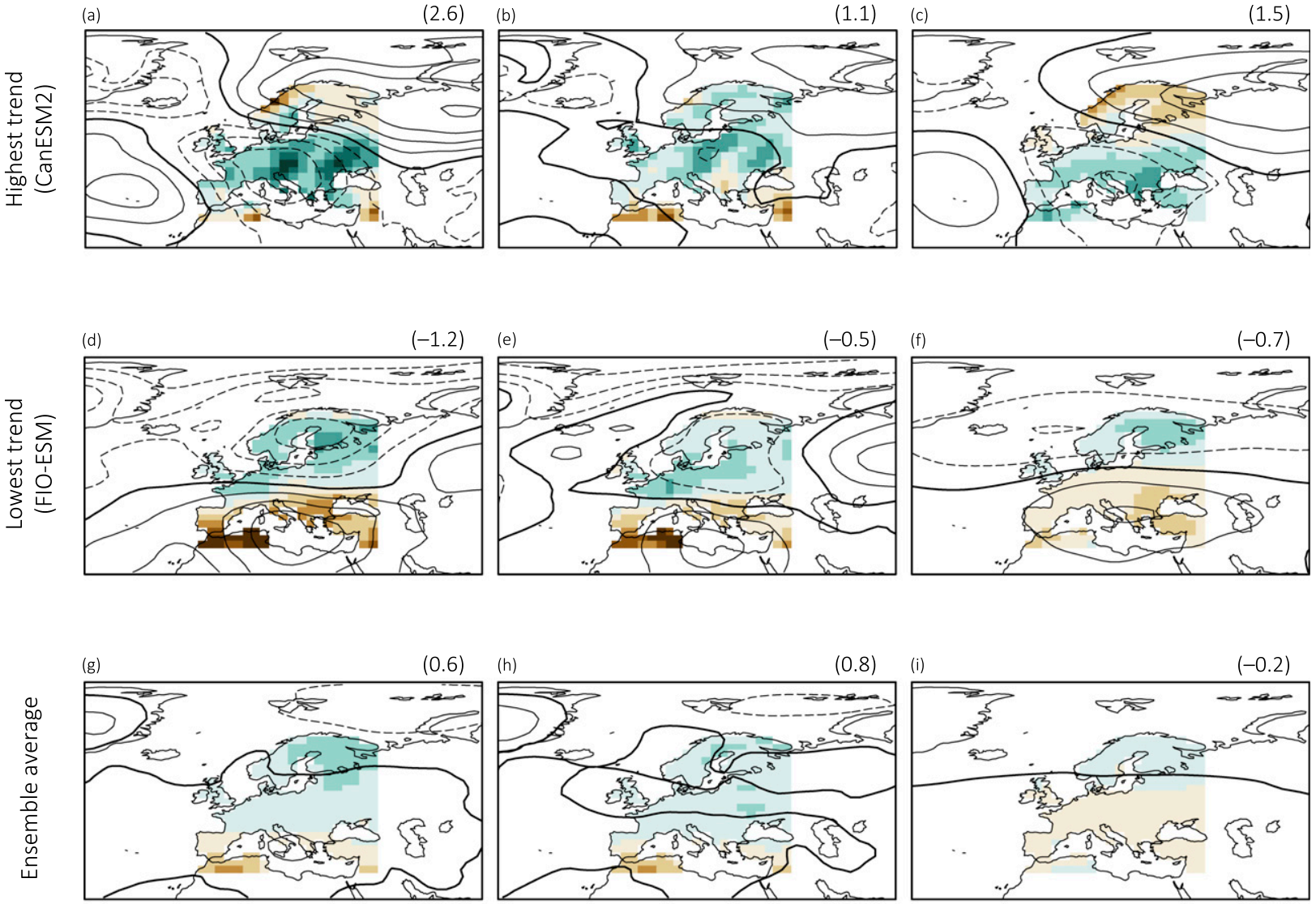

(h)

(0.8)

(i)
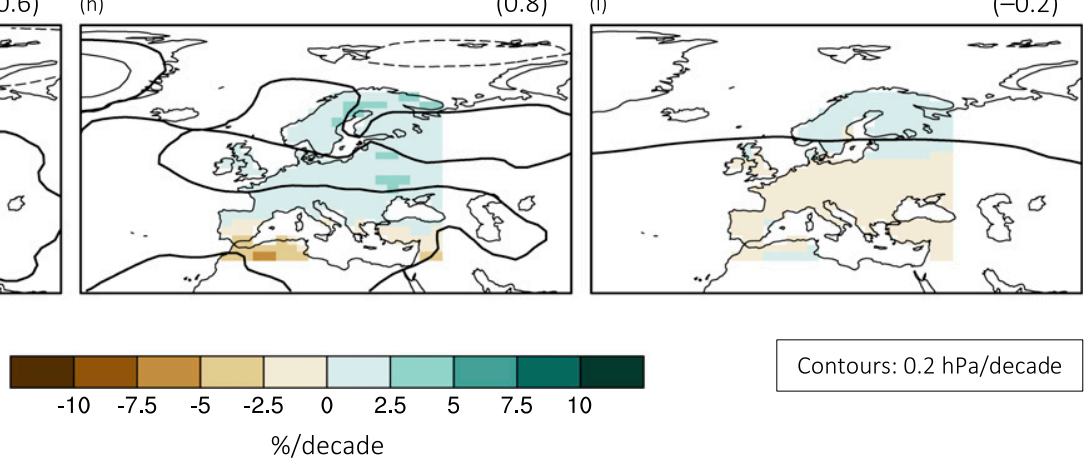

Contours: $0.2 \mathrm{hPa} /$ decade

FIG. 8. As in Fig. 7, but showing results for precipitation trends $\left(\%\right.$ decade $\left.^{-1}\right)$. Numbers in parentheses at the top right of each panel indicate the weighted area average of precipitation trends.

Residual differences between the adjusted trends are related to the different large-scale responses of models to anthropogenic forcing and to other structural and parametric differences not accounted for by dynamical adjustment. After removing the effect of circulation, the dynamically adjusted trends are closer to the multimodel ensemble trends.

\section{c. Sensitivity of the multimodel mean response of temperature and precipitation to the choice of the ensemble}

We analyze the sensitivity of the forced multimodel mean response of temperature and precipitation to the ensemble size and to the choice of the models included. To this aim we compute the area-average trend from each model simulation and the ensemble-mean areaaverage trends from subsets of two models, three models, etc. The mean and the standard deviation of these trends give an indication of the most probable value and of the spread of the estimates of the forced response if only one, two, three, etc., simulations were available. When selecting subensembles of two models or more, intervals are constructed by choosing 780 random combinations from all the possible ones.

This analysis is performed on both the original and dynamically adjusted trends of winter temperature and precipitation simulated by the 40 CMIP5 models in the period 2006-50 over Europe, Scandinavia, and the Iberian Peninsula. Results from the unadjusted (blue) and adjusted (red) simulations are compared in Fig. 10. In all cases the interval width decreases nonlinearly with the number of model runs included in the subensembles, as expected. Furthermore, the trend spreads obtained from the adjusted subensembles are smaller than those 
(a)

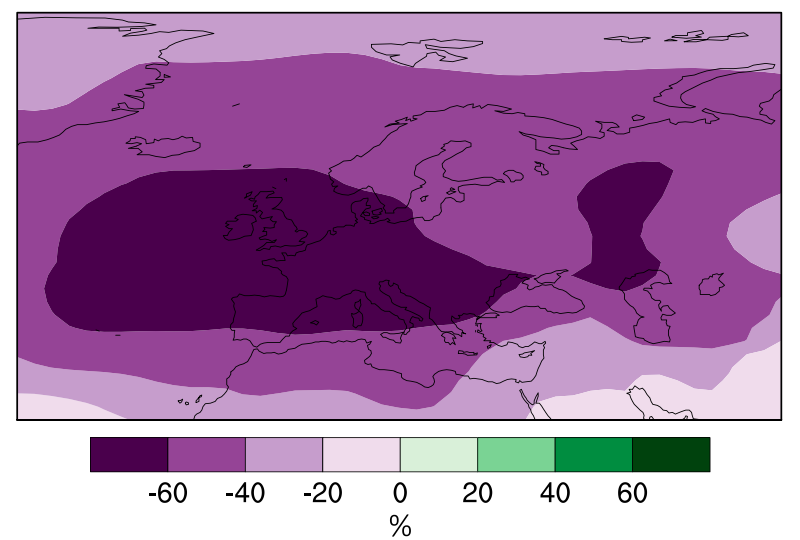

(b)

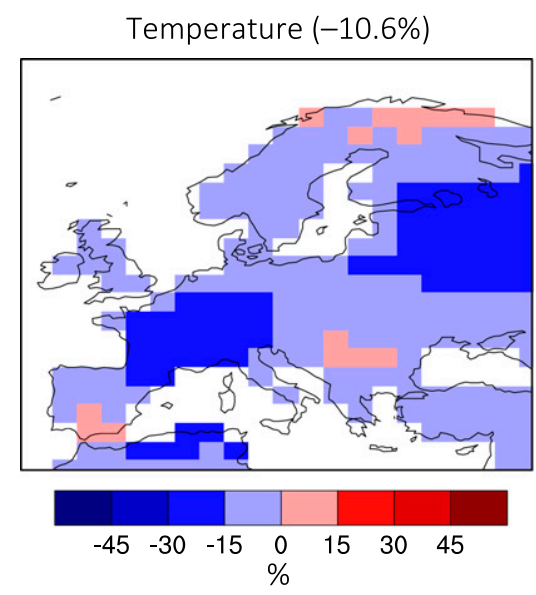

(c)

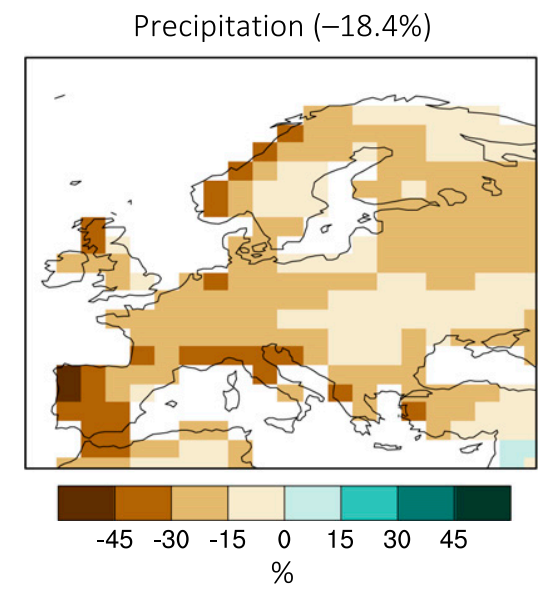

FIG. 9. Percent change in the standard deviation of the 2006-50 winter trends of (a) sea level pressure, (b) temperature, and (c) precipitation from the 40 CMIP5 models after removing the effect of the first six EOFs using the CTL version of dynamical adjustment. Numbers in parentheses indicate weighted area-average values.

computed from the unadjusted simulations, as the effect of atmospheric circulation is removed. An offset between the average trends computed from the original and the adjusted runs is observed. This can be caused either by chance or by a nonzero multimodel response of atmospheric circulation to anthropogenic forcing, contributing to temperature and precipitation trends. In the first case the offset would originate from the removal of the effect of random realizations of unforced atmospheric variability not averaging out in the ensemble mean as a result of insufficient sampling. In this hypothesis the average values computed by the dynamically adjusted trends would represent a better estimate of the forced signal than those obtained from the original runs. Because of its purely statistical nature, such offset should tend to disappear as the size of the ensemble increases. In the second case, a multimodel response of atmospheric circulation to anthropogenic forcing would represent a caveat to the application of dynamical adjustment, as by applying this method a component of the forced response would be removed. This second hypothesis is investigated in the following section.

\section{Identification of a forced response of atmospheric circulation in a multimodel ensemble}

A forced response of atmospheric circulation might manifest itself through changes in the structure of the modes of sea level pressure variability, nonzero longterm trends in the principal components of preexisting modes, or changes in their amplitude and frequency. In the results presented so far atmospheric circulation is sampled from each model individually. To identify changes in the multimodel ensemble, however, a common set of multimodel EOFs is defined from the dataset obtained by merging the last 100 years of the control simulations of the models. Changes in the structure of circulation patterns are sought by comparing the leading EOFs of winter SLP variability over the Euro-Atlantic region in preindustrial simulations and under historical and RCP 8.5 forcing conditions. To this end, multimodel EOFs are computed from the three datasets obtained by merging the last 30 winters of each of the 40 preindustrial control simulations, the winters in the periods 1961-90 and 2070-99, respectively. The four leading modes account together for about $77 \%-78 \%$ of the overall SLP variability in the three periods. Results show no indication of major changes in the structure of the first EOF of atmospheric circulation in response to the forcing (Figs. S8a-c in the supplemental material). An analysis of the regression maps suggests no major changes in the temperature and precipitation effect of the leading mode of variability (Figs. S8d-i) compared to the greater diversity across models (Figs. S6 and S7).

A statistically significant response of atmospheric circulation variability to anthropogenic forcing is identified 

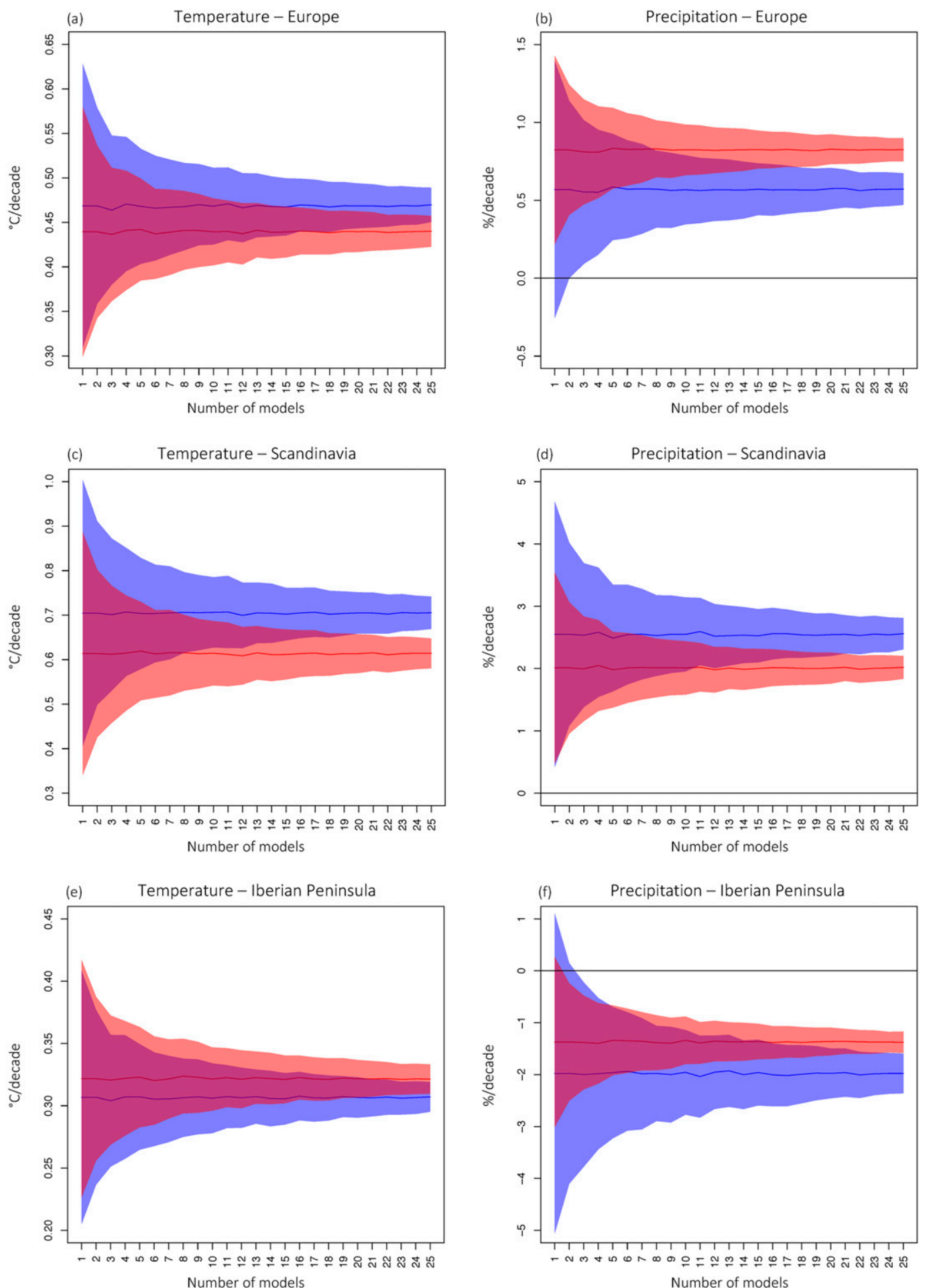

FIG. 10. Mean (lines) and plus/minus one standard deviation (shading) values of area-average (left) temperature and (right) precipitation trends in the period 2006-50 as estimated from 40 CMIP5 models and from 780 multimodel means obtained from subensembles of an increasing number of simulations. Blue colors correspond to the original trends and red colors to the dynamically adjusted trends (CTL version, six EOFs included). Values are computed over (a),(b) Europe, (c),(d) Scandinavia, and (e),(f) the Iberian Peninsula. 
2006-2050 average dynamical contribution

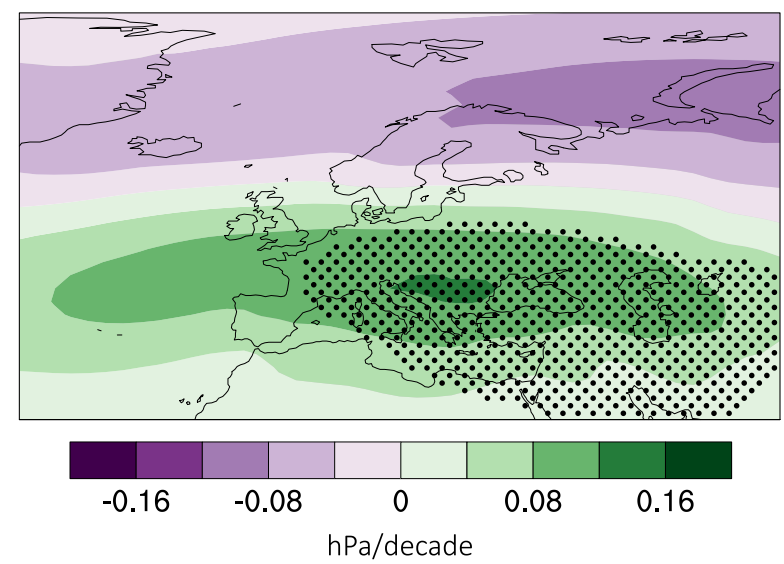

FIG. 11. Multimodel mean dynamical contribution (six EOFs, CTL version) to winter sea level pressure trends simulated by 40 CMIP5 models in the period 2006-50. Stippling highlights areas where changes are significantly different from zero at a $95 \%$ confidence level.

in winter sea level pressure simulated by the multimodel ensemble in the period 2006-50. Figure 11 shows the multimodel mean dynamical contribution to the 2006-50 winter SLP trends, defined by the effect on sea level pressure trends of the first six EOFs (sampled for each model from the last 100 years of its preindustrial control simulation). This is characterized by enhanced anticyclonic circulation over central Europe, the Mediterranean Sea, and part of the Atlantic Ocean and by negative values north of Scandinavia. The Student's $t$ test is applied at each grid point to test whether the mean of the 40 trends is significantly different from zero. Areas where the multimodel mean values are different from zero at a $95 \%$ confidence level are highlighted by stippling. This only covers a region roughly corresponding to the southern center of action of the leading EOF. The dynamical contribution in the area of the northern center of action is found to be statistically significant at a $90 \%$ confidence level (not shown). This is because SLP variability is large compared to the dynamical response at higher latitudes. The trends in Fig. 11 are similar to the modeled response of sea level pressure to anthropogenic forcing already identified in previous studies (e.g., Gillett et al. 2003) and suggest a strengthening of the westerly flow over northern Europe. Trends in Fig. 11 are similar to the multimodel mean of winter SLP in the same period (Fig. S9 in the supplemental material) but exclude the thermodynamic response of sea level pressure, mainly consisting of an area of positive trends over Greenland forced by ice melting. Figure 11 thus only shows the dynamic response of sea level pressure to anthropogenic forcing. Note that
Fig. 11 shows the same SLP trends appearing in contour lines in Figs. 7i and 8i.

The multimodel mean dynamical contributions to the 2006-50 winter temperature and precipitation trends are computed by including the effect of the first six EOFs sampled for each model from the last 100 years of its control simulation. The effect of sea level pressure variability on the ensemble average trends is shown in Figs. 12a,d, with the two patterns being very similar to the regression maps associated with the first EOF (Fig. S8). The multimodel mean forced dynamical response in SLP tends to increase the warming over most of the region and has a weak cooling contribution only over the southern part of the domain. A pronounced dipolar structure is observed for the multimodel mean dynamical contribution to precipitation trends. The forced SLP response enhances precipitation over Scandinavia and reduces it over the rest of Europe, generating pronounced drying over the southeastern part of the domain. The overall effect of the first six EOFs of SLP (Fig. 11) is consistent with the multimodel mean dynamical contributions to temperature and precipitation trends, producing warmer and wetter conditions over Scandinavia and drier conditions over central Europe (Figs. 12a,d). Note that Figs. 12a,d show the same temperature and precipitation trends in Figs. $7 \mathrm{i}$ and 8 i. Figures $12 \mathrm{~b}$,e show the multimodel mean winter temperature and precipitation trends in the period 2006-50. As in the case of SLP trends in Fig. 11, stippled areas indicate significant changes at a $95 \%$ confidence level. Figures $12 \mathrm{c}, \mathrm{f}$ show the ratios in percent between the multimodel mean dynamical contributions and the multimodel mean trends. These are computed by dividing the multimodel mean dynamical contributions by the multimodel mean trends and then multiplying by a factor of 100 to express the differences as percentages. The estimated dynamically forced contribution to temperature trends over Scandinavia reaches values up to $15 \%-20 \%$ of the multimodel mean response to warming, and even higher values are found for precipitation. Similar results are obtained for winter trends in the period 2006-99, with larger regions showing statistically significant changes (not shown). This indicates that the multimodel mean dynamical contribution in Fig. 11 is not time dependent and that it is a robust feature of the response of atmospheric circulation to anthropogenic forcing in the CMIP5 ensemble.

The estimates of the multimodel mean dynamical contributions to sea level pressure, temperature, and precipitation trends are mainly affected by the first few EOFs and are not critically sensitive to the number of modes included in the analysis. This is shown in Figs. S10-S12 of the supplemental material, reporting 
2006-2050

average dynamical contributions
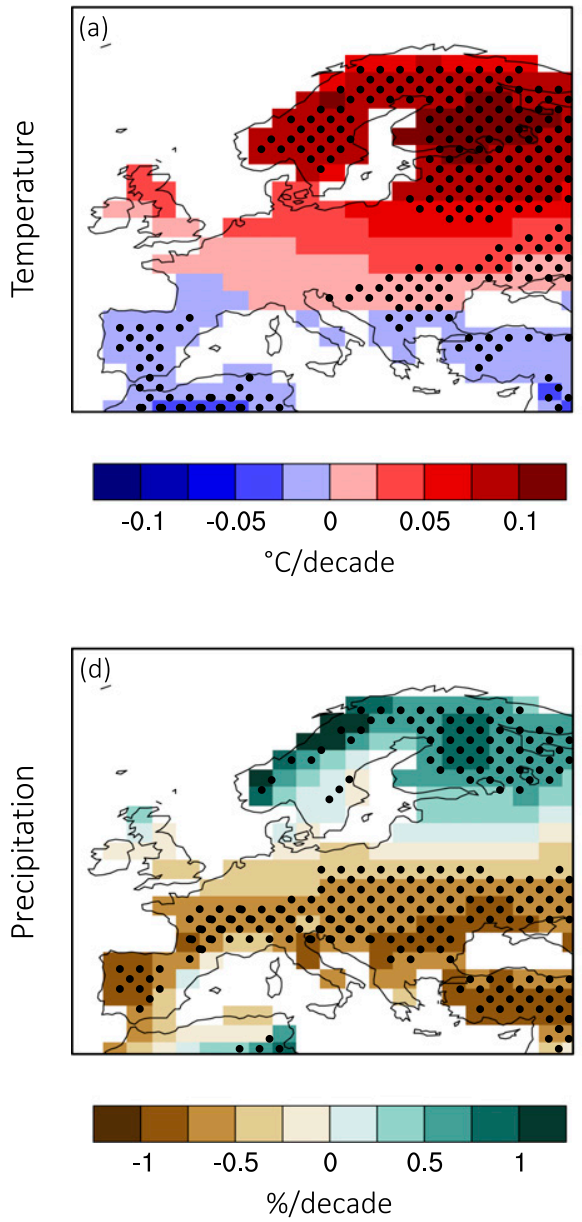

2006-2050

average trends
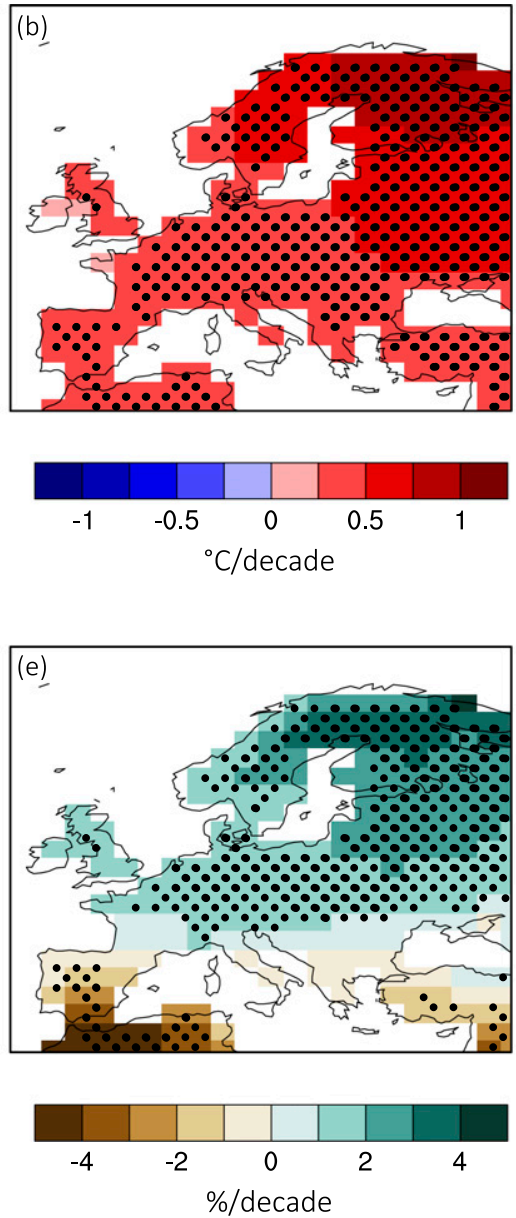

2006-2050

percentage ratios
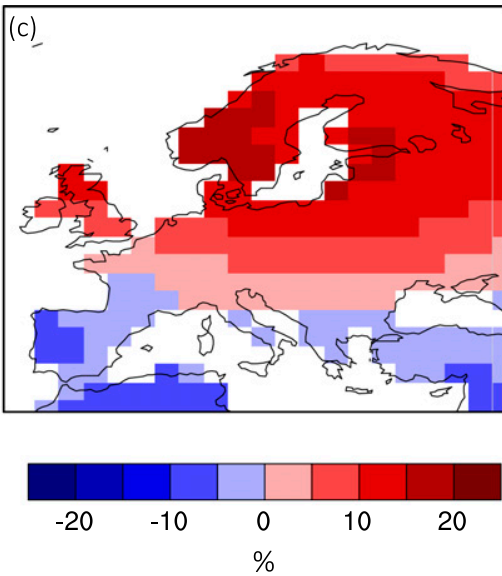

FIG. 12. Multimodel mean dynamical contributions of the first six EOFs (CTL version) to (a) temperature and (d) precipitation trends in the period 2006-50 as simulated by 40 CMIP5 models. Multimodel mean (b) temperature and (e) precipitation trends in the same period. Ratios in percent between the multimodel mean dynamical contributions and multimodel mean trends for (c) temperature and (f) precipitation. Stippling in (a),(b),(d),(e) highlights areas where changes are significantly different from zero at a $95 \%$ confidence level. Note that very high values over the latitudinal band spanning from northern Spain to the Black Sea in (f) are a consequence of the nearzero multimodel trends over the same region in (e).

the multimodel mean dynamical contributions to winter sea level pressure, temperature, and precipitation trends in the period 2006-50 computed from a different number of EOFs (1-10). Figures S13 and S14 in the supplemental material show the dynamical contributions to winter 2006-50 sea level pressure, temperature, and precipitation trends estimated from CESM-IC by removing the effect of the first four EOFs with the CTL version of dynamical adjustment. The response simulated by the initial condition ensemble is similar to the one computed from the 40 CMIP5 models.

The contribution of the forced SLP response to the area-average trends of temperature and precipitation over Europe, Scandinavia, and the Iberian Peninsula is quantified by the offsets introduced by dynamical adjustment in Fig. 10, which can be expressed as percentages of the original trends. The dynamical contributions to the multimodel ensemble average temperature and precipitation trends (Figs. 12a,d) are respectively equal to $+6 \%$ and $-45 \%$ over Europe (Figs. 10a,b; note that the multimodel mean precipitation trend is small). The forced response of circulation enhances trends over Scandinavia, causing an increase of the multimodel mean trends equal to $+13 \%$ and $+21 \%$ of the original temperature and precipitation trends, respectively (Figs. 10c,d). Circulation does not have a strong influence on temperature trends 
TABLE A1. List of the CMIP5 models included in the analysis. (Expansions of acronyms are available online at http://www.ametsoc.org/ PubsAcronymList.)

\begin{tabular}{|c|c|c|c|}
\hline Model version & Institution(s) and country & Model version & Institution(s) and country \\
\hline ACCESS1.0 & CSIRO and BoM, Australia & GFDL-ESM2M & NOAA/GFDL, United States \\
\hline ACCESS1.3 & CSIRO and BoM, Australia & GISS-E2-H & NASA GISS, United States \\
\hline BCC_CSM1.1 & BCC, China & GISS-E2-H-CC & NASA GISS, United States \\
\hline BCC_CSM1.1(m) & BCC, China & GISS-E2-R & NASA GISS, United States \\
\hline BNU-ESM & BCC, China & GISS-E2-R-CC & NASA GISS, United States \\
\hline CanESM2 & CCCma, Canada & HadGEM2-AO & $\begin{array}{l}\text { National Institute of } \\
\text { Meteorological Research (NIMR), } \\
\text { South Korea }\end{array}$ \\
\hline CCSM4 & NCAR, United States & HadGEM2-CC & Met Office, United Kingdom \\
\hline CESM1(BGC) & NSF, DOE, and NCAR, United States & HadGEM2-ES & Met Office, United Kingdom \\
\hline CESM1(CAM5) & NSF, DOE, and NCAR, United States & INM-CM4.0 & INM, Russia \\
\hline CESM1(WACCM) & NSF, DOE, and NCAR, United States & IPSL-CM5A-LR & IPSL, France \\
\hline CMCC-CESM & CMCC, Italy & IPSL-CM5A-MR & IPSL, France \\
\hline CMCC-CM & CMCC, Italy & IPSL-CM5B-LR & IPSL, France \\
\hline CMCC-CMS & CMCC, Italy & MIROC5 & $\begin{array}{l}\text { Atmosphere and Ocean Research } \\
\text { Institute (AORI), JAMSTEC, and } \\
\text { National Institute of Environmental } \\
\text { Studies (NIES), Japan }\end{array}$ \\
\hline CNRM-CM5 & $\begin{array}{l}\text { Centre National de Recherches } \\
\text { Météorologiques (CNRM) } \\
\text { and CERFACS, France }\end{array}$ & MIROC-ESM & AORI, JAMSTEC, and NIES, Japan \\
\hline CSIRO Mk3.6.0 & CNRM and CERFACS, France & MIROC-ESM-CHEM & AORI, JAMSTEC, and NIES, Japan \\
\hline EC-EARTH & EC-EARTH international consortium & MPI-ESM-LR & MPI, Germany \\
\hline FGOALS-g2 & $\begin{array}{l}\text { IAP and Tsinghua University } \\
\text { (THU), China }\end{array}$ & MPI-ESM-MR & MPI, Germany \\
\hline FIO-ESM & NOAA/GFDL, United States & MRI-CGCM3 & $\begin{array}{l}\text { Meteorological Research Institute } \\
\text { (MRI), Japan }\end{array}$ \\
\hline GFDL CM3 & NOAA/GFDL, United States & NorESM1-M & $\begin{array}{l}\text { Norwegian Climate Centre } \\
\text { (NCC), Norway }\end{array}$ \\
\hline GFDL-ESM2G & NOAA/GFDL, United States & NorESM1-ME & NCC, Norway \\
\hline
\end{tabular}

over the Iberian Peninsula ( $-5 \%$; Fig. 10e), while its effect on precipitation trends over the same region is particularly pronounced (-31\%; Fig. 10f).

Several previous studies discussed the response of atmospheric circulation to anthropogenic forcing in CMIP5 models (e.g., Barnes et al. 2014; Gillett and Fyfe 2013; Corti et al. 1999). Barnes and Polvani (2013) identified a poleward shift of about $1^{\circ}$ latitude north of the North Atlantic eddy-driven jet by the end of the twenty-first century in the RCP8.5 scenario. This effect could not be identified in the present work owing to the coarse resolution of the simulations in the multimodel ensemble, which were interpolated to the latitudelongitude grid used in CESM-IC, with a resolution of $1.9^{\circ} \times 2.5^{\circ}$.

CMIP5 models are affected by systematic biases in several features of atmospheric circulation such as blocking frequency and duration (Dunn-Sigouin and Son 2013) and North Atlantic cyclones (Zappa et al. 2013). These biases might influence the structure of the dynamical contributions to temperature and precipitation trends shown in Fig. 12. Consequently, the atmospheric circulation response to anthropogenic forcing remains uncertain (Shepherd 2014).

\section{Summary and conclusions}

The influence of atmospheric circulation on simulated temperature and precipitation trends is analyzed by sampling monthly winter sea level pressure variability in a CESM initial condition ensemble and in a CMIP5 multimodel ensemble. Dynamical adjustment reduces the spread of simulated trends by removing the effect of internally generated and externally forced circulation changes. Five versions of an EOF-based adjustment method are described, and their performance in reducing the spread of simulated temperature and precipitation trends are compared.

The version of dynamical adjustment calibrated on the preindustrial control simulation (CTL) is applied to the CMIP5 multimodel ensemble to reduce the uncertainty on the mean response to anthropogenic forcing of winter temperature and precipitation over Europe in the period 2006-50. Although an analysis on CMIP5 monthly winter 
sea level pressure over the Euro-Atlantic sector reveals no indication of changes in the structure of the main modes of atmospheric circulation, a statistically significant forced response of sea level pressure is identified in the period 2006-50. This is associated with nonzero dynamical contributions to winter temperature and precipitation trends. Deser et al. (2012b) showed that atmospheric circulation can critically affect individual realizations of future climate. Our results indicate that the dynamical contribution to the 2006-50 multimodel mean trends over Europe is relatively small for temperature but substantially higher for precipitation. The multimodel forced response of atmospheric circulation results in a slightly amplified warming and in a reduced wettening over Europe. Its impact depends on location and is pronounced over Scandinavia for both temperature and precipitation and over the Iberian Peninsula for precipitation.

The effect of atmospheric circulation internal variability on temperature and precipitation trends can be considered largely independent and additive to the forced response only in regions where the effect of anthropogenic forcing on sea level pressure variability is small. Over such regions dynamical adjustment can be applied to estimate the forced temperature and precipitation response with higher accuracy, or with the same accuracy using fewer simulations. The SLP response to anthropogenic forcing represents a caveat to the application of dynamical adjustment, as by using this method a component of the forced response in temperature and precipitation might be removed. Dynamical adjustment is applied assuming that changes in sea level pressure drive a component of temperature and precipitation variability. The regression approach on which the method is based, however, does not strictly assume causality, and there are circumstances in which sea level pressure is affected by temperatures, especially over land (Fischer et al. 2007).

This work contributes to the understanding of the impact of atmospheric circulation in CMIP5 models and to the quantification of its effect as a source of uncertainty on future trends at the regional and local scales. Our findings are in line with those from previous publications (e.g., Thompson et al. 2015; Deser et al. 2016) in showing that internal variability gives rise to large uncertainty in climate projections. The identification of a statistically significant multimodel response of atmospheric circulation to anthropogenic forcing adds to the ongoing debate on human-induced changes in internal variability. Further analysis might extend to the two hemispheres and to other vertical levels in the atmosphere and might focus on the nature of the projected trends of sea level pressure, with the aim of determining to what extent these changes in circulation are contributed by a thermodynamic response to increased temperatures.

Acknowledgments. We acknowledge the World Climate Research Programme's Working Group on Coupled Modelling and the Working Group on Regional Climate, which are responsible for CMIP and EUROCORDEX, and we thank the climate modeling groups (see Table A1 in the appendix) for producing and making available their model output. For CMIP the U.S. Department of Energy's Program for Climate Model Diagnosis and Intercomparison provides coordinating support and led development of software infrastructure in partnership with the Global Organization for Earth System Science Portals. This work was supported by the Swiss National Science Foundation Grant 144332. The authors wish to thank David W. J. Thompson, Christoph Raible, and three anonymous reviewers for their insightful comments.

\section{APPENDIX}

\section{CMIP5 Models}

CMIP5 models included in the analysis of the multimodel ensemble are listed in Table A1.

\section{REFERENCES}

Abdi, H., 2010: Partial least squares regression and projection on latent structure regression (PLS regression). Wiley Interdiscip. Rev.: Comput. Stat., 2, 97-106, doi:10.1002/wics.51.

Barnes, E. A., and L. Polvani, 2013: Response of the midlatitude jets, and of their variability, to increased greenhouse gases in the CMIP5 models. J. Climate, 26, 7117-7135, doi:10.1175/ JCLI-D-12-00536.1.

— E. Eunn-Sigouin, G. Masato, and T. Woollings, 2014: Exploring recent trends in Northern Hemisphere blocking. Geophys. Res. Lett., 41, 638-644, doi:10.1002/2013GL058745.

Casty, C., H. Wanner, J. Luterbacher, J. Esper, and R. Böhm, 2005: Temperature and precipitation variability in the European Alps since 1500. Int. J. Climatol., 25, 1855-1880, doi:10.1002/ joc.1216.

Cattiaux, J., R. Vautard, C. Cassou, P. Yiou, V. Masson-Delmotte, and F. Codron, 2010: Winter 2010 in Europe: A cold extreme in a warming climate. Geophys. Res. Lett., 37, L20704, doi:10.1029/2010GL044613.

Ceppi, P., S. C. Scherrer, A. M. Fischer, and C. Appenzeller, 2012: Revisiting Swiss temperature trends 1959-2008. Int. J. Climatol., 32, 203-213, doi:10.1002/joc.2260.

Collins, M., B. Booth, B. Bhaskaran, G. R. Harris, J. M. Murphy, D. M. H. Sexton, and M. J. Webb, 2011: Climate model errors, feedbacks and forcings: A comparison of perturbed physics and multi-model ensembles. Climate Dyn., 36, 1737-1766, doi:10.1007/s00382-010-0808-0.

Corti, S., F. Molteni, and T. N. Palmer, 1999: Signature of recent climate change in frequencies of natural atmospheric circulation regimes. Nature, 398, 799-802, doi:10.1038/19745. 
Deser, C., R. Knutti, S. Solomon, and A. S. Phillips, 2012a: Communication of the role of natural variability in future North American climate. Nat. Climate Change, 2, 775-779, doi:10.1038/nclimate1562.

- A. Phillips, V. Bourdette, and H. Teng, 2012b: Uncertainty in climate change projections: The role of internal variability. Climate Dyn., 38, 527-546, doi:10.1007/s00382-010-0977-x.

M. A. Alexander, and B. V. Smoliak, 2014: Projecting North American climate over the next 50 years: Uncertainty due to internal variability. J. Climate, 27, 2271-2296, doi:10.1175/JCLI-D-13-00451.1.

_, L. Terray, and A. S. Phillips, 2016: Forced and internal components of winter air temperature trends over North America during the past 50 years: Mechanisms and implications. J. Climate, 29, 2237-2258, doi:10.1175/JCLI-D-15-0304.1.

Doblas-Reyes, F. J., and Coauthors, 2013: Initialized near-term regional climate change prediction. Nat. Commun., 4, 1715, doi:10.1038/ncomms2704.

Dunn-Sigouin, E., and S.-W. Son, 2013: Northern Hemisphere blocking frequency and duration in the CMIP5 models. J. Geophys. Res. Atmos., 118, 1179-1188, doi:10.1002/ jgrd.50143.

Fischer, E. M., and C. Schär, 2009: Future changes in daily summer temperature variability: Driving processes and role for temperature extremes. Climate Dyn., 33, 917-935, doi:10.1007/ s00382-008-0473-8.

— S. I. Seneviratne, P. L. Vidale, D. Lüthi, and C. Schär, 2007: Soil moisture-atmosphere interactions during the $2003 \mathrm{Eu}-$ ropean summer heat wave. J. Climate, 20, 5081-5099, doi:10.1175/JCLI4288.1.

_ U. Beyerle, and R. Knutti, 2013: Robust spatially aggregated projections of climate extremes. Nat. Climate Change, $\mathbf{3}, 1033$ 1038, doi:10.1038/nclimate2051.

Frankcombe, L. M., M. H. England, M. E. Mann, and B. A. Steinman, 2015: Separating internal variability from the externally forced climate response. J. Climate, 28, 8184-8202, doi:10.1175/JCLI-D-15-0069.1.

Gillett, N. P., and J. C. Fyfe, 2013: Annular mode changes in the CMIP5 simulations. Geophys. Res. Lett., 40, 1189-1193, doi:10.1002/grl.50249.

— , F. W. Zwiers, A. J. Weaver, and P. A. Stott, 2003: Detection of human influence on sea-level pressure. Nature, 422, 292294, doi:10.1038/nature 01487.

_ R. J. Allan, and T. J. Ansell, 2005: Detection of external influence on sea level pressure with a multi-model ensemble. Geophys. Res. Lett., 32, L19714, doi:10.1029/2005GL023640.

Hannachi, A., I. T. Jolliffe, and D. B. Stephenson, 2007: Empirical orthogonal functions and related techniques in atmospheric science: A review. Int. J. Climatol., 27, 1119-1152, doi:10.1002/ joc.1499.

Hawkins, E., and R. Sutton, 2009: The potential to narrow uncertainty in regional climate predictions. Bull. Amer. Meteor. Soc., 90, 1095-1107, doi:10.1175/2009BAMS2607.1.

— jections of regional precipitation change. Climate Dyn., 37, 407-418, doi:10.1007/s00382-010-0810-6.

Hsu, C., and F. Zwiers, 2001: Climate change in recurrent regimes and modes of Northern Hemisphere atmospheric variability. J. Geophys. Res., 106, 20 145-20 159, doi:10.1029/ 2001JD900229.

Hurrell, J. W., 1995: Decadal trends in the North Atlantic Oscillation: Regional temperatures and precipitation. Science, $\mathbf{2 6 9}$, 676-679, doi:10.1126/science.269.5224.676.
_ 1996: Influence of variations in extratropical wintertime teleconnections on Northern Hemisphere temperature. Geophys. Res. Lett., 23, 665-668, doi:10.1029/96GL00459.

— and Coauthors, 2013: The Community Earth System Model: A framework for collaborative research. Bull. Amer. Meteor. Soc., 94, 1339-1360, doi:10.1175/BAMS-D-12-00121.1.

Jacob, D., and Coauthors, 2007: An inter-comparison of regional climate models for Europe: Model performance in presentday climate. Climatic Change, 81, 31-52, doi:10.1007/ s10584-006-9213-4.

Jun, M., R. Knutti, and D. W. Nychka, 2008: Spatial analysis to quantify numerical model bias and dependence. J. Amer. Stat. Assoc., 103, 934-947, doi:10.1198/016214507000001265.

Kjellström, E., L. Bärring, D. Jacob, R. Jones, G. Lenderink, and C. Schär, 2007: Modelling daily temperature extremes: Recent climate and future changes over Europe. Climatic Change, 81, 249-265, doi:10.1007/s10584-006-9220-5.

Knutti, R., and J. Sedláček, 2012: Robustness and uncertainties in the new CMIP5 climate model projections. Nat. Climate Change, 3, 369-373, doi:10.1038/nclimate1716.

— , and Coauthors, 2008: A review of uncertainties in global temperature projections over the twenty-first century. J. Climate, 21, 2651-2663, doi:10.1175/2007JCLI2119.1.

—_, R. Furrer, C. Tebaldi, J. Cermak, and G. A. Meehl, 2010: Challenges in combining projections from multiple climate models. J. Climate, 23, 2739-2758, doi:10.1175/ 2009JCLI3361.1.

_ - D. Masson, and A. Gettelman, 2013: Climate model genealogy: Generation CMIP5 and how we got there. Geophys. Res. Lett., 40, 1194-1199, doi:10.1002/grl.50256.

Lorenz, E. N., 1969: Atmospheric predictability as revealed by naturally occurring analogues. J. Atmos. Sci., 26, 636-646, doi:10.1175/1520-0469(1969)26<636:APARBN>2.0.CO;2.

Lucarini, V., S. Calmanti, A. Dell'Aquila, P. M. Ruti, and A. Speranza, 2007: Intercomparison of the Northern Hemisphere winter mid-latitude atmospheric variability of the IPCC models. Climate Dyn., 28, 829-848, doi:10.1007/ s00382-006-0213-x.

Masson, D., and R. Knutti, 2011: Climate model genealogy. Geophys. Res. Lett., 38, L08703, doi:10.1029/2011GL046864.

Murphy, J. M., D. M. H. Sexton, D. N. Barnett, G. S. Jones, M. J. Webb, M. Collins, and D. A. Stainforth, 2004: Quantification of modelling uncertainties in a large ensemble of climate change simulations. Nature, 430, 768-772, doi:10.1038/ nature02771.

North, G. R., T. L. Bell, R. F. Cahalan, and F. J. Moeng, 1982: Sampling errors in the estimation of empirical orthogonal functions. Mon. Wea. Rev., 110, 699-706, doi:10.1175/ 1520-0493(1982)110<0699:SEITEO>2.0.CO;2.

Palmer, T. N., 1999: A nonlinear dynamical perspective on climate prediction. J. Climate, 12, 575-591, doi:10.1175/ 1520-0442(1999)012<0575:ANDPOC >2.0.CO;2.

— , U. Andersen, A. Alessandri, P. Cantelaube, and M. Davey, 2004: Development of a European Multimodel Ensemble System for Seasonal to Interannual Prediction (DEMETER). Bull. Amer. Meteor. Soc., 85, 853-872, doi:10.1175/BAMS-85-6-853.

Pennell, C., and T. Reichler, 2011: On the effective number of climate models. J. Climate, 24, 2358-2367, doi:10.1175/ 2010JCLI3814.1.

Quadrelli, R., and J. M. Wallace, 2004: A simplified linear framework for interpreting patterns of Northern Hemisphere wintertime climate variability. J. Climate, 17, 3728-3744, doi:10.1175/ 1520-0442(2004)017<3728:ASLFFI>2.0.CO;2. 
Randall, D. A., and Coauthors, 2007: Climate models and their evaluation. Climate Change 2007: The Physical Science Basis, S. Solomon et al., Eds., Cambridge University Press, 589-662.

Robock, A., 2000: Volcanic eruptions and climate. Rev. Geophys., 38, 191-219, doi:10.1029/1998RG000054.

Saffioti, C., E. M. Fischer, S. C. Scherrer, and R. Knutti, 2016: Reconciling observed and modelled temperature and precipitation trends over Europe by adjusting for circulation variability Geophys. Res. Lett., 43, 8189-8198, doi:10.1002/2016GL069802.

Shepherd, T. G., 2014: Atmospheric circulation as a source of uncertainty in climate change projections. Nat. Geosci., 7, 703708, doi:10.1038/ngeo2253.

Shukla, J., 1998: Predictability in the midst of chaos: A scientific basis for climate forecasting. Science, 282, 728-731, doi:10.1126/science.282.5389.728.

Smoliak, B. V., J. M. Wallace, M. T. Stoelinga, and T. P. Mitchell, 2010: Application of partial least squares regression to the diagnosis of year-to-year variations in Pacific Northwest snowpack and Atlantic hurricanes. Geophys. Res. Lett., 37, L03801, doi:10.1029/2009GL041478.

,--1, P. Lin, and Q. Fu, 2015: Dynamical adjustment of the Northern Hemisphere surface air temperature field: Methodology and application to observations. J. Climate, 28, 16131629, doi:10.1175/JCLI-D-14-00111.1.

Solomon, A., and Coauthors, 2011: Distinguishing the roles of natural and anthropogenically forced decadal climate variability. Bull. Amer. Meteor. Soc., 92, 141-156, doi:10.1175/2010BAMS2962.1.

Stainforth, D. A., and Coauthors, 2005: Uncertainty in predictions of the climate response to rising levels of greenhouse gases. Nature, 433, 403-406, doi:10.1038/nature03301.

Stephenson, D. B., A. Hannachi, and A. O'Neill, 2004: On the existence of multiple climate regimes. Quart. J. Roy. Meteor. Soc., 130, 583-605, doi:10.1256/qj.02.146.

Stoner, A. M. K., K. Hayhoe, and D. J. Wuebbles, 2009: Assessing general circulation model simulations of atmospheric teleconnection patterns. J. Climate, 22, 4348-4372, doi:10.1175/ 2009JCLI2577.1.

Taylor, K. E., R. J. Stouffer, and G. A. Meehl, 2012: An overview of CMIP5 and the experiment design. Bull. Amer. Meteor. Soc. 93, 485-498, doi:10.1175/BAMS-D-11-00094.1.
Tebaldi, C., and R. Knutti, 2007: The use of the multi-model ensemble in probabilistic climate projections. Philos. Trans. Roy. Soc. London, 365A, 2053-2075, doi:10.1098/ rsta.2007.2076

Thompson, D. W. J., J. M. Wallace, and G. C. Hegerl, 2000: Annular modes in the extratropical circulation. Part II: Trends. J. Climate, 13,1018-1036, doi:10.1175/1520-0442(2000)013<1018: AMITEC $>2.0 . \mathrm{CO} ; 2$.

——, — P. D. Jones, and J. J. Kennedy, 2009: Identifying signatures of natural climate variability in time series of global-mean surface temperature: Methodology and insights. J. Climate, 22, 6120-6141, doi:10.1175/ 2009JCLI3089.1.

— E. A. Barnes, C. Deser, W. E. Foust, and A. S. Phillips, 2015: Quantifying the role of internal climate variability in future climate trends. J. Climate, 28, 6443-6456, doi:10.1175/ JCLI-D-14-00830.1.

Trenberth, K. E., 2002: Evolution of El Niño-Southern Oscillation and global atmospheric surface temperatures. J. Geophys. Res., 107, 4065, doi:10.1029/2000JD000298.

Van den Dool, H., 1994: Searching for analogues, how long must we wait? Tellus, 46A, 314-324, doi:10.3402/tellusa.v46i3.15481.

Vautard, R., and P. Yiou, 2009: Control of recent European surface climate change by atmospheric flow. Geophys. Res. Lett., 36, L22702, doi:10.1029/2009GL040480.

Wallace, J. M., Y. Zhang, and J. A. Renwick, 1995: Dynamic contribution to hemispheric mean temperature trends. Science, 270, 780-783, doi:10.1126/science.270.5237.780.

, Q. Fu, B. V. Smoliak, P. Lin, and C. M. Johanson, 2012: Simulated versus observed patterns of warming over the extratropical Northern Hemisphere continents during the cold season. Proc. Natl. Acad. Sci. USA, 109, 14337-14342, doi:10.1073/pnas.1204875109.

Yang, F., and M. E. Schlesinger, 2001: Identification and separation of Mount Pinatubo and El Niño-Southern Oscillation land surface temperature anomalies. J. Geophys. Res., 106, $14757-$ 14770, doi:10.1029/2001JD900146.

Zappa, G., L. C. Shaffrey, and K. I. Hodges, 2013: The ability of CMIP5 models to simulate North Atlantic extratropical cyclones. J. Climate, 26, 5379-5396, doi:10.1175/JCLI-D-12-00501.1. 